CHAPTER 9

\title{
Respiration and its measurement in surface marine waters
}

\author{
Carol Robinson ${ }^{1}$ and Peter J. Ie B. Williams ${ }^{2}$ \\ 1 Plymouth Marine Laboratory, UK \\ 2 School of Ocean Sciences, University of Wales, Bangor, UK
}

\section{Outline}

This chapter reviews the current state of knowledge of the process and measurement of microplankton respiration in marine surface waters. The principal approaches are outlined and their potentials and limitations discussed. A global database, containing 1662 observations has been compiled and analyzed for the spatial and temporal distribution of surface water respiration. The database is tiny compared to that of photosynthesis and biased with respect to season, latitude, community structure, and depth. Measurements and models show that the major portions of respiration lies in that attributable to bacteria (12-59\%) and to algae (8-70\%). The mean of the volumetric rates of respiration in the upper $10 \mathrm{~m}$ of the open ocean is $3.3 \pm 0.15 \mathrm{mmol} \mathrm{O}_{2} \mathrm{~m}^{-3} \mathrm{~d}^{-1}$ and that of depth-integrated open-ocean respiration $116 \pm 8.5 \mathrm{mmol} \mathrm{O}_{2} \mathrm{~m}^{-2} \mathrm{~d}^{-1}$. A global estimate of $13.5 \mathrm{Pmol} \mathrm{O}_{2} \mathrm{a}^{-1}$ is derived from the mean depth-integrated rate, which significantly exceeds contemporary estimates of ocean plankton production (2.3-4.3 $\mathrm{Pmol} \mathrm{O}_{2} \mathrm{a}^{-1}$ ). This difference is at variance with the results of mass-balance calculations, which suggest a small difference (ca. 0.18) between oceanic production and respiration. The reasons for this are discussed.

\subsection{Introduction}

This chapter reviews our present understanding of the process of marine planktonic respiration, and the methodologies used for its determination. We collate the global database of measured respiration and use it to assess how far we can determine seasonal, regional, and latitudinal patterns of distribution. Measurements of respiration are not yet routine within national and international marine biogeochemical programs. A significant relationship between respiration and more routinely measured parameters would substantially progress our ability to determine its spatial and temporal variability. We investigate whether such a relationship exists. Linked to this is the importance of an appreciation of the distribution of respiration within the microbial food web, and so improved food web model parameterization and verification. When considered on comparable time and space scales, the balance between plankton respiration and photosynthesis indicates the potential amount of photosynthetically fixed carbon available for export from the upper mixed layer. We assume that the epipelagic zone of the open oceans approaches this ideal, and analyze the distributions of respiration and photosynthesis in order to assess the global balance between photosynthesis and respiration.

\subsection{Available approaches and their constraints}

Rates of planktonic respiration can be derived in a number of ways: (i) from the measurement of the rate of production/consumption of a product 
or reactant, (ii) the assay of an appropriate respiratory enzyme or enzyme system, (iii) predictions from biomass, and (iv) from inverse models of the community composition and activity.

\subsubsection{Flux of products and reactants}

\section{Principle of the approach}

This approach is based on the measurement of the change of a reactant (e.g. oxygen) or product (e.g. carbon dioxide) of respiration over a period of time (characteristically 12 or $24 \mathrm{~h}$ ) in the dark. The basic requirement is the ability to analyze the sample, a replicate or a representative body of water at point(s) during the incubation period. The most common method is the in vitro dark bottle incubation, which was originally developed as a means of accounting for respiration during the determination of photosynthesis within the "light/dark" bottle protocol. For reasons of sensitivity, oxygen is the usual determinant and comprises most (>90\%) of the global database. Carbon dioxide (either $\mathrm{pCO}_{2}$ or total dissolved inorganic carbon, DIC) has also been used (Johnson et al. 1983, 1987; Robinson and Williams 1999; Robinson et al. 1999). Dark incubations are necessary for the measurement of respiration via oxygen or carbon dioxide flux to eliminate concurrent counter fluxes of the same compounds by photosynthesis. The dark bottles are incubated at in situ temperature, either deployed on an in situ rig (usually alongside samples incubated for determination of primary production), or held in temperature controlled incubators. In order to measure respiration occurring in both the light and the dark, an extension of the oxygen flux method has been developed. This entails subtracting measurements of net community production (derived from the oxygen flux during a "light" bottle incubation) from concurrent measurements of gross photosynthesis (derived from ${ }^{18} \mathrm{O}_{2}$ production from a "light" bottle incubation of a sample spiked with ${ }^{18} \mathrm{O}$ labeled water, Bender et al. 1987; Grande et al., $1989 a, b)$.

The in vitro nature of the incubation potentially can give rise to errors, which has prompted attempts to determine respiration by measuring oxygen and carbon dioxide changes in situ. This relies on the ability to sample consistently within the same water mass and to account for nonrespiratory processes which would alter the concentration of the chosen reactant. Depending on the timescale, these latter processes could include air-sea exchange, evaporation and precipitation, and production/dissolution of calcium carbonate. The use of sulfur hexafluoride (Upstill-Goddard et al. 1991) significantly increases the ability to track a particular water mass over several days, thereby allowing consecutive estimates of community respiration to be made. However, in order to obtain a satisfactory signal to noise ratio the spatial variability of the reactant within the labeled area needs to be small in comparison with the time-dependent change in the dark period due to respiration. Low latitude, low energy gyre systems with long welldefined dark periods offer the most favorable physical circumstances, however respiration rates in such systems are characteristically low (see Williams and Purdie 1991). High latitude, high energy systems with short and poorly delineated dark periods and high spatial variability offer the least promising circumstances.

\section{Limit of detection}

The limit of detection of the in vitro approach is determined by a combination of (i) the precision of the analytical technique, (ii) the number of replicates, (iii) the ambient concentration, and (iv) the incubation time. The analytical methods for oxygen and carbon dioxide work near the practical limits of volumetry (estimated to be $\approx 0.02 \%$, Robinson and Williams 1991), so the ambient concentration is the main determinant of the sensitivity of the analytical method. In Table 9.1 the theoretical limits of oxygen and carbon dioxide derived rate measurements have been estimated. As oxygen solubility is strongly temperature dependant in the oceans, the calculation of this gas has been made for a range of temperatures. These are estimates of best performance; the precision of the analyses falls away in areas of high particulate load (see Hopkinson and Smith, Chapter 8) and under fieldwork conditions. The final determinant is the time of incubation. In the euphotic zone, where there is a diel cycle of oxygen and carbon dioxide flux, then 12 or $24 \mathrm{~h}$ incubations 
Table 9.1 Calculation of the precision limits for the measurement of changes in oxygen and total inorganic carbon concentrations

\begin{tabular}{|c|c|c|c|c|}
\hline Determinant & $\begin{array}{l}\text { Water temperature } \\
\left({ }^{\circ} \mathrm{C}\right)\end{array}$ & $\begin{array}{l}\text { Ambient concentration } \\
\left(\mathrm{mmol} \mathrm{m}^{-3}\right)\end{array}$ & $\begin{array}{l}\text { Coefficient of variation } \\
\text { of the method }{ }^{b}(\%)\end{array}$ & $\begin{array}{l}\text { Limit of analytical } \\
\text { detection }^{c}\left(\mathrm{mmol} \mathrm{m}^{-3}\right)\end{array}$ \\
\hline $\mathrm{CO}_{2}$ & & 2100 & 0.02 & 0.6 \\
\hline $\mathrm{O}_{2}$ & 0 & 350 & 0.02 & 0.1 \\
\hline $\mathrm{O}_{2}$ & 15 & 250 & 0.02 & 0.07 \\
\hline $\mathrm{O}_{2}$ & 25 & 200 & 0.02 & 0.06 \\
\hline
\end{tabular}

have a logic. In deeper water, the diel cycle has little or no relevance, and the important consideration here is the continued linearity of the rates.

\section{Random and systematic errors}

The measurement of respiration will be subject to a number of random and potential systematic errors. Random errors derive from two sources: (i) the analytical method for the measurement of the reactant and (ii) a form of time-dependent randomness between the incubated replicates. The former can be determined from the precision of the zero time measurements, the latter by the difference between the precision of the zero time replicates and that of the incubated replicates. These errors need to be reported, as they set the precision and therefore the significance of the observations. Typical median coefficient of variation of the zero time dissolved oxygen replicates during fieldwork conditions fall in the region of 0.015$0.07 \%$ while that of dark incubated dissolved oxygen replicates are $0.08-0.15 \%$ (Robinson et al. 2002a,b). Typical means of the standard errors of respiration measurements derived from dissolved oxygen flux range from 0.06 to $0.5 \mathrm{mmolO}_{2} \mathrm{~m}^{-3} \mathrm{~d}^{-1}$ (Williams and Purdie 1991; Robinson and Williams 1999; Robinson et al. 2002a,b; Williams et al. 2004). The median standard error of the oxygen flux derived rates of respiration collated for this review is $0.2 \mathrm{mmolO}_{2} \mathrm{~m}^{-3} \mathrm{~d}^{-1} \quad(n=1012)$. The determination of respiration from the coulometric analysis of dissolved inorganic carbon flux is less precise and the analytical method requires frequent calibration to maintain its accuracy. Reported means of the standard errors of the combined respiration and net community production determinations derived from DIC flux during fieldwork are $1-1.5 \mathrm{mmol} \mathrm{C} \mathrm{m}^{-3} \mathrm{~d}^{-1}(n=19)$, and of respiration measurements alone, $0.8 \mathrm{mmol} \mathrm{C} \mathrm{m}{ }^{-3} \mathrm{~d}^{-1}(n=11)$ (Robinson and Williams 1999; Robinson et al. 1999, 2002a).

Errors of accuracy (systematic errors) are always difficult to assess, particularly when no reference is available. We have categorized these nonrandom errors under three headings: procedural errors, errors of containment, and errors of interpretation. The separation is not perfect but suffices for the purpose of discussion.

\section{Procedural errors}

The necessity to derive respiration measurements from oxygen and similar parameter changes in the dark gives rise to two forms of error: (i) omission in the determined rate of light-associated respiration and (ii) a time-dependent run down of respiration due to a decrease in the concentration of the substrates that fuel respiration.

There are two forms of respiration that occur exclusively or predominantly in the light-notably the Mehler and the RUBISCO oxidase/photorespiration reactions. These, and their implications for the measurement of respiration, have been discussed by Raven and Beardall (Chapter 3) and Williams and del Giorgio (Chapter 1). They cannot be measured by the conventional dark bottle approach. Whether this is a problem, or a blessing, depends upon the purpose of the measurements. The argument is made in Chapter 1 that these reactions have little to do with organic metabolism-particularly the Mehler 
reaction-and that for much ecological work its omission from the respiration measurement is more likely a gain rather than a loss. This would not be the case for fundamental physiological work directed to photon capture and quantum yield when these two processes would need to be taken into account. The circumstances surrounding the RUBISCO oxidase/photorespiration reactions are less straightforward in this respect.

The run down of respiration due to the exhaustion of substrates has received the attention of a number of workers. Of 34 published time courses (Williams and Grey 1970; Williams 1981; Harrison 1986; Hopkinson et al. 1989; Kruse 1993; Biddanda et al. 1994; Pomeroy et al. 1994; Sampou and Kemp 1994; Blight et al. 1995; Arístegui et al. 1996; Carlson et al. 1999; Robinson et al. 1999; Robinson 2000; Robinson et al. 2002b), more than $80 \%$ show a linear rate of decrease in oxygen concentration (i.e. no observable change in respiration rate) for at least the first 6 days of incubation. In only two inshore studies (Williams 1981; Pomeroy et al. 1994), where respiration rates were high (from 5 to $11 \mathrm{mmolO}_{2} \mathrm{~m}^{-3} \mathrm{~d}^{-1}$ ) were monotonic decreases or increases in oxygen concentration seen during incubations of less than 1 day. Where nonlinearities have been encountered it is possible to calculate the error that would have been incurred by using the simple two time point $24 \mathrm{~h}$ incubation and this varies from 2 to $20 \%$; the very high proportion of linear time courses suggests that the lower estimate is the more representative one.

Long dark incubations give rise to more subtle problems in that they may disrupt any inherent diel cycle. Recent studies have highlighted the diel synchrony of growth of photosynthetic prokaryotes in both culture and open-ocean situations (Zubkov et al. 2000; Jacquet et al. 2001). A $24 \mathrm{~h}$ dark incubation of a picophytoplankton dominated community would therefore disrupt this light: dark cell cycle. The consequences and importance of such an effect are unknown.

\section{Errors of containment}

All in vitro approaches (be they in $50 \mathrm{~cm}^{3}$ bottles or $10 \mathrm{~m}^{3}$ mesocosms) involve containment. Containment may cause two categories of error; (i) the sample size will involve omission of part of the heterotrophic community, (ii) the container itself may impact the enclosed population giving rise to so-called "bottle" effects.

The omission of organisms will have two consequences: (i) there will be loss of a component of respiration, (ii) the absence of a predator will remove grazing pressure and so control on the abundance of the prey will be lost. Larger organisms occur at sufficiently low abundances that they are poorly sampled by in vitro procedures, and so community respiration is in this respect underestimated. It is possible to quantify the effect in order to establish its significance. Distributions of individual abundances and cumulative respiration rates can be derived from observed or theoretical profiles of biomass. Figure 9.1 (based on Platt and Denman 1977) shows the theoretical distribution of both abundance and cumulative respiration with size. The intersection of the two straight lines shows the individual size (ca. $50 \mu \mathrm{m}$ ) above which the organisms are poorly represented (less than $10 \mathrm{dm}^{-3}$ ) in samples taken for in vitro studies. However, by this size, in excess of 99\% of calculated respiration is accounted for by the smaller size fractions (see circles in the figure). An extensive analysis is summarized in Fig. 9.15, and suggests a figure of $3 \%$ of respiration associated with organisms greater than $100 \mu \mathrm{m}$. Hernandez-Leon and Ikeda (Chapter 5), on the other hand, suggest a larger contribution of zooplankton to total respiration, in the order of 6 to $10 \%$ of the total water column respiration. Thus, although the omission of large organisms does not introduce a substantial error to estimates of community respiration, the larger size classes cannot be ignored.

Omission of a predator will have a potential secondary effect on respiration deriving from the increase of biomass of the prey and its associated respiration. Pomeroy et al. (1994) showed the increase in bacterial numbers and substrate assimilation rates which can occur during bottle incubations, which they concluded was due to the disruption of the grazer/prey link within the food web. These effects may be expected to be greater in size fractionation studies in which the size fraction greater than for example, $1 \mu \mathrm{m}$ is removed. Sherr et al. (1999) found a 2 to 8 fold increase in bacterial activity of a $1 \mu \mathrm{m}$ filtrate incubated for 2-3 days. 


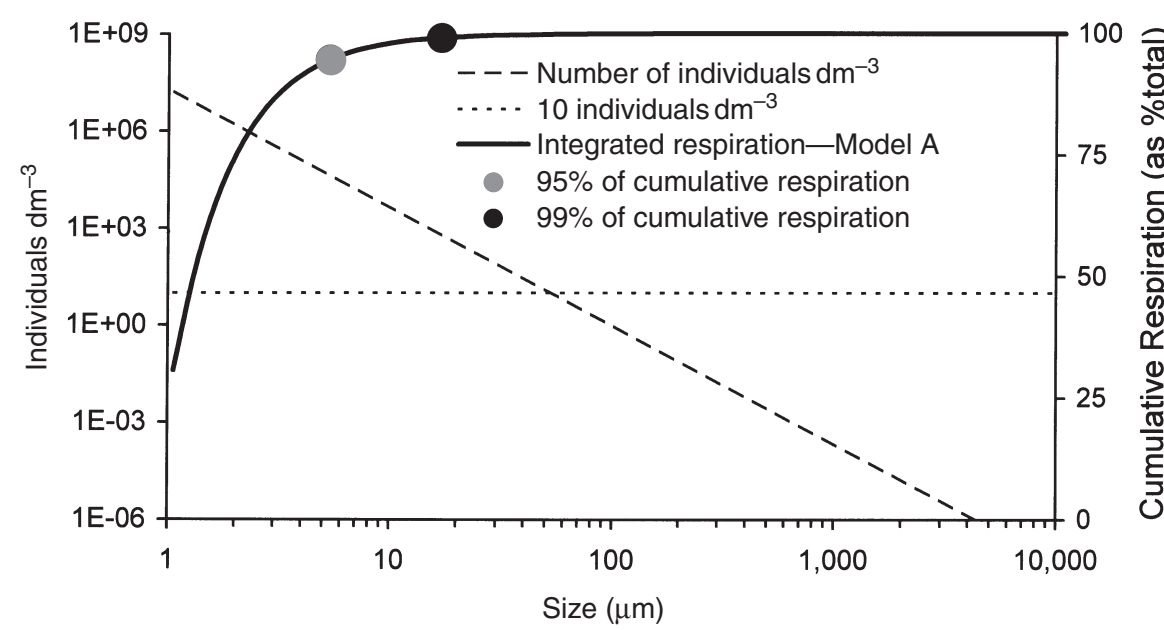

Figure 9.1 Calculated size distribution of numbers of individuals and cumulative respiration. The circles are the points of $99 \%$ and $95 \%$ cumulative respiration. Details are given in Fig. 9.14.

Where concomitant measurements have been made of changes in bacterial abundance and respiration rate, it has been found that whereas the former may increase, this surprisingly is not accompanied with an increase in community respiration rate (Pomeroy et al. 1994; Blight et al. 1995).

Aside from purported bottle-induced increases in bacterial numbers, there are well-defined instances of contamination effects, notably from heavy metals. This was one of the foci of the Planktonic Rate Processes in the Oligotrophic Oceans (PRPOOS) study and it was found (Marra and Heinemann 1984) that with careful attention to detail and cleanliness these effects could be overcome.

\section{Errors of interpretation}

The oxygen technique determines the decrease of oxygen in the dark and makes the assumption that this can be attributed to the physiological process of respiration. This assumption has been challenged by Pamatmat (1997), who argued that the decomposition of hydrogen peroxide, which gives rise to the production of oxygen, could aliaise the respiration measurements, depending upon the technique used to measure oxygen. Polarographic oxygen sensors and mass spectrometers will accurately record the changes in oxygen concentration; as a consequence the decomposition of hydrogen peroxide would be recorded, quite properly, as the production of oxygen in the dark and therefore give rise to an underestimation of respiration. This would not occur if the Winkler reaction were used, as the reagents will react with hydrogen peroxide and so would be falsely but fortuitously recorded as the equivalent amount of oxygen-hence recording no net change due to the decomposition of hydrogen peroxide.

Pamatmat further discussed a cycle of hydrogen peroxide, which he claimed would give rise to the net production of $1 / 2$ mole of oxygen per cycle. Pamatmat's proposed hydrogen peroxide/oxygen cycle can only give rise to net oxygen production at the expense of reduced structures. Whereas such a supply of organic proton and electron donors may exist in the types of environment he studied (tide pools, saline ponds), they would not accumulate in significant quantities in either shelf or offshore waters.

Significantly, where hydrogen peroxide concentrations are reported for coastal and offshore areas they are characteristically in the range of 2-50 $\mathrm{nmol} \mathrm{dm}^{-3}$ (Herut et al. 1998; Hanson et al. 2001; Yuan and Shiller, 2001). The flux rates are in the range, $8-230 \mathrm{nmol} \mathrm{dm}^{-3} \mathrm{~d}^{-1}$ (Moffett and Zafiriou 1993; Yocis et al. 2000; Yuan and Shiller 2001). Both concentrations and fluxes of hydrogen peroxide are 
low in relation to their oxygen counterparts, and close to, or more often below, the sensitivity of the methods used to measure in vitro oxygen fluxes. In polluted waters, hydrogen peroxide concentrations are higher $\left(8-100 \mathrm{nmol} \mathrm{dm}^{-3}\right.$; Herut et al. 1998), but even here they are near to or beyond the limit of the Winkler oxygen technique and so are a minor source of error in relation to the high respiratory oxygen fluxes observed in such waters.

Thus, present understanding of hydrogen peroxide cycling implies that the rates would be beyond the sensitivity of the Winkler incubation technique in open-ocean environments. Thus, Pamatmat's concerns over the use of the oxygen technique for both respiration and production would appear to be unfounded.

Anomalous observations and reconciliation with other measures of plankton activity and in situ derived respiration rates

One virtue of the in vitro oxygen flux technique is the ability to detect anomalous results; for example, apparent "negative" respiration rates or oxygen production in the dark. Williams (2000) analyzed a dataset of 293 observations after filtering the data for occasions where the gross production or respiration rate was less than twice its standard error or where "impossible" values of negative gross production or respiration occurred. This filtering process reduced the dataset by $5-10 \%$, but the frequency of the negative respiration rates was not differentiated within this. We have access to the original titration data of 859 of the in vitro dark oxygen flux data collected for this review. Within this dataset, on only nine occasions did the final concentration of oxygen exceed the initial concentration, and so produce an anomalous "negative" respiration rate.

A different anomaly reported in the literature (Robinson and Williams 1999) is the determination of higher than expected respiratory quotients $\left(\Delta \mathrm{CO}_{2} /-\Delta \mathrm{O}_{2}\right)$ derived from the concurrent measurement of oxygen consumption and dissolved inorganic carbon production during a dark incubation. The authors were unable to account for these measurements without invoking the occurrence of metabolic processes such as methanogenesis in the aerobic euphotic zone of the Arabian Sea.
Several studies have addressed the question of whether in vitro estimates of plankton activity are representative of $i n$ situ rates. With regard to primary production, differences of $\sim 25 \%$ between in vitro and in situ derived rates have been found (Williams and Purdie 1991; Daneri 1992; Chipman et al. 1993; Rees et al. 2001). Bearing in mind the difficulty of recreating an appropriate light field for in vitro estimates of primary production and the practical limitations to in situ work, it seems reasonable to suggest that the difference between in vitro and in situ derived rates of plankton respiration would be of a comparable or lesser magnitude.

\subsubsection{Electron transport system (ETS) assay}

The use of enzymatic indicators to estimate "potential" respiration is gaining acceptance due to their sensitivity ( $\left.<0.1 \mathrm{mmol} \mathrm{O}_{2} \mathrm{~m}^{-3} \mathrm{~d}^{-1}\right)$, especially for mesopelagic waters (del Giorgio 1992; Harrison et al. 2001; Arístegui and Harrison 2002; Arístegui et al. 2002; and see Hernández-León and Ikeda, Chapter 5). These methods are not yet routinely used in biogeochemical studies. ETS activity measurements have to be converted to in situ respiration rates by empirically determined relationships between ETS activity and respiration derived from dissolved oxygen flux. Such data interpretation faces problems, but no more so than those of other commonly used rate process techniques $\left({ }^{14} \mathrm{C}\right.$ and ${ }^{3} \mathrm{H}$-thymidine; del Giorgio 1992) or extrapolations of remotely sensed ocean color data to sea surface chlorophyll and primary production estimates (Sullivan et al. 1993).

The ETS method estimates the maximum activity of the enzymes associated with the respiratory ETSs in both eukaryotic and prokaryotic organisms. The rate of reduction of a tetrazolium salt (2-( $p$-iodophenyl)-3-( $p$-nitrophenyl)-5phenyl tetrazolium chloride (INT)) is used as an indicator of electron transport activity, and so oxygen consumption or carbon dioxide production (Packard 1971; Kenner and Ahmed 1975; Arístegui and Montero 1995). The enzymatic rates are corrected to in situ temperature using the Arrhenius equation. Activation energies of between 46 and $67 \mathrm{~kJ} \mathrm{~mol}^{-1}$ have been measured (Arístegui and 
Montero 1995; Arístegui et al. 2002). The ETS technique measures the maximum capacity of the terminal oxidation system in vitro (in the physiological sense). In vivo rates are controlled by the rates of oxidative phosphorylation and so the maximum rate is not thought to be achieved in the whole cell. The suppression is not constant, varying with taxonomic group and physiological state (Packard 1985), and so needs to be established empirically. Typical algorithms used are $\log R\left(\mathrm{mg} \mathrm{O}_{2} \mathrm{~m}^{-3} \mathrm{~d}^{-1}\right)=$ $0.357+0.750 \log$ ETS $\left(r^{2}=0.75 ; n=197 ;\right.$ Arístegui and Montero 1995) for oceanic surface waters or $R=$ ETS $\times 0.086$ (Christensen et al. 1980) for 200$1000 \mathrm{~m}$ depths. The error associated with such conversions is estimated to be $\sim \pm 30 \%$ (Arístegui and Montero 1995, and see Hernández-León and Ikeda, Chapter 5).

\subsubsection{Derivation from biomass}

Given measurements or estimates of biomass within the planktonic community and appropriate biomass-specific rates of metabolism, a rate of respiration may be calculated. Methods are available to determine or estimate the biomass of most components of the planktonic community, although they are often very demanding of time and skill. An alternative to determining the biomass of individual organisms or groups is to use generalized derivations of biomass, either from observations (Sheldon et al. 1972) or theory (Platt and Denman 1978), within the size spectrum found in marine plankton. These can be coupled with allometric equations for respiration versus weight or size of the organism (Blanco et al. 1998). There is some consensus over the rate versus size relationship for respiration for larger plankton (see Fenchel, Chapter 4, and HernándezLeón and Ikeda, Chapter 5), but as size decreases the basic assumption that one can specify metabolic rates becomes less secure: bacteria for instance probably exhibit the greatest metabolic range of all freeliving organisms. Despite its obvious limitations the approach offers a valuable constraint to field observations of the distribution of respiration within the planktonic size spectrum (Robinson et al. 1999, 2002b).

\subsubsection{Derivation from activity and growth efficiencies}

Rates of primary production, bacterial production, and to a lesser extent microzooplankton herbivory and bacterivory are much more frequently determined than rates of plankton community respiration. Therefore, if the growth efficiency of each of these plankton groups can be sufficiently constrained, the respiration rate of each group can be calculated and the community respiration rate derived by summation. Unfortunately growth efficiencies, particularly those of the bacterial fraction, are not well constrained. While this approach has been used with some success-the summed estimated respiration of each trophic group falling within $50 \%$ of the measured community respiration (Robinson and Williams 1999; Robinson et al. 1999, 2002b) - the reliance upon an estimate of the growth efficiencies is the greatest limitation to this technique.

\subsubsection{Inverse analysis}

A different approach to the determination of community respiration or the respiration of a particular size class or group of the plankton, is to use inverse analysis (e.g. Vezina and Platt 1988). The procedure incorporates observations of rates or states and searches for the best fit of the unknown metabolic rate to the field data. It is potentially a very powerful approach as it is substantially, but not wholly, objective. However, the analysis is only as good as the data incorporated, and with many datasets, several parameters will not be known, requiring subjective interpretation. Fasham et al. (1999) used a size structured ecosystem model forced by measured water column integrated primary production and heterotrophic bacterial production to derive the size distribution of community respiration during a diatom bloom in the north east Atlantic. Ducklow et al. (2000) used equations of carbon flow through phytoplankton, zooplankton, and bacteria, along with the constraint of measured community respiration to estimate bacterial respiration, and Anderson and Ducklow (2001) used a simple steady-state model of the microbial loop to examine the reliability 
of measured bacterial production, growth efficiency, and hence respiration. As more datasets are collected which encompass concurrent rate and state measurements of most of the plankton groups, this procedure will become more commonplace.

\subsubsection{Future analytical methods}

The importance of plankton respiration measurements to an understanding of carbon flow through the microbial food web, and the relatively few observations currently available from traditional methods, lead us to continually seek new approaches which could improve our understanding of the spatial and temporal variability of community respiration as well as that of components of the plankton community.

The activity of the enzyme isocitrate dehydrogenase (IDH) has been investigated in batch cultures of marine bacteria in relation to carbon dioxide production and oxygen consumption (Packard et al. 1996). Rates of carbon dioxide production were predicted from models of second-order enzyme kinetics throughout the different phases of the cultures with an $r^{2}$ greater than 0.84 (Packard et al. 1996; Roy and Packard 2001). The potential to use this enzyme as an index of bacterial respiratory production of carbon dioxide in the ocean awaits further investigation and improvement.

Luz and Barkan (2000) have recently introduced a method to estimate time-integrated rates of respiration and photosynthesis from the difference between the triple isotope $\left({ }^{16} \mathrm{O},{ }^{17} \mathrm{O}\right.$, and $\left.{ }^{18} \mathrm{O}\right)$ composition of atmospheric and dissolved oxygen and the rate of air-sea oxygen exchange. Their estimates of gross oxygen production agreed well with rates determined by bottle incubations in the Sea of Galilee and with seasonal cycles of production determined in upper ocean waters near Bermuda (Bender 2000). The advantage of the method is that it integrates over week to month periods, something that is impossible to achieve with bottle incubations. The disadvantages are the reliance on knowledge of gas exchange rates, (an associated error of about 30\%) and of the fractionation by photosynthesis and respiration, and the cost and skill required for mass spectrometric analysis of oxygen isotopes. However these latter problems are likely to diminish with time.

\subsection{Community respiration rates}

\subsubsection{Overview of the data}

Previous collations of community respiration data have gathered a few hundred measurements worldwide. Williams (2000) analyzed a dataset of 293 observations and assessed the interconnections between plankton community respiration, net community production, and gross production. Rivkin and Legendre (2001) compiled community respiration data from 12 studies $(n=100)$ in order to test the predictive capability of their equation relating bacterial growth efficiency to temperature and their assertion that the major part of community respiration is attributable to bacteria. Robinson et al. (2002a) collated data from six oligotrophic studies and four upwelling studies in order to calculate a mean respiration rate for oligotrophic regions of $2.4 \mathrm{mmol} \mathrm{O}_{2} \mathrm{~m}^{-3} \mathrm{~d}^{-1}(<0.7-12.7 ; n=51)$ and a mean respiration rate in upwelling areas of $6.5 \mathrm{mmol} \mathrm{O}_{2} \mathrm{~m}^{-3} \mathrm{~d}^{-1}(0-33.4 ; n=132)$.

In the present study, we have combined these datasets and augmented them with recently published data, unpublished data of our own, and unpublished and published data kindly supplied by colleagues (Arístegui, J., Gonzalez, N., Lefevre, D., and Morris, P., personal communication). The data can be accessed at www.pml.ac.uk/amt/data/Respiration.xls. This database will continue to be developed and maintained. We anticipate that we have acquired ca. $80 \%$ of the existing surface water respiration data. Data have not been used in the present analysis when the rate is less than twice the standard error (95\% confidence limits). The combined dataset consists of 1662 respiration data (693 separate stations), collected between 1980 and 2002, from open ocean, coastal upwelling and shelf sea environments (Robinson and Williams 1993, 1999; Kiddon et al. 1995; Pomeroy et al. 1995; Cota et al. 1996; Lefevre et al. 1997; Eissler and Quinones 1999; Robinson et al. 1999, 2002a,b; Sherry et al., 1999; Daneri et al. 2000; Hitchcock et al. 2000; Moncoiffe 


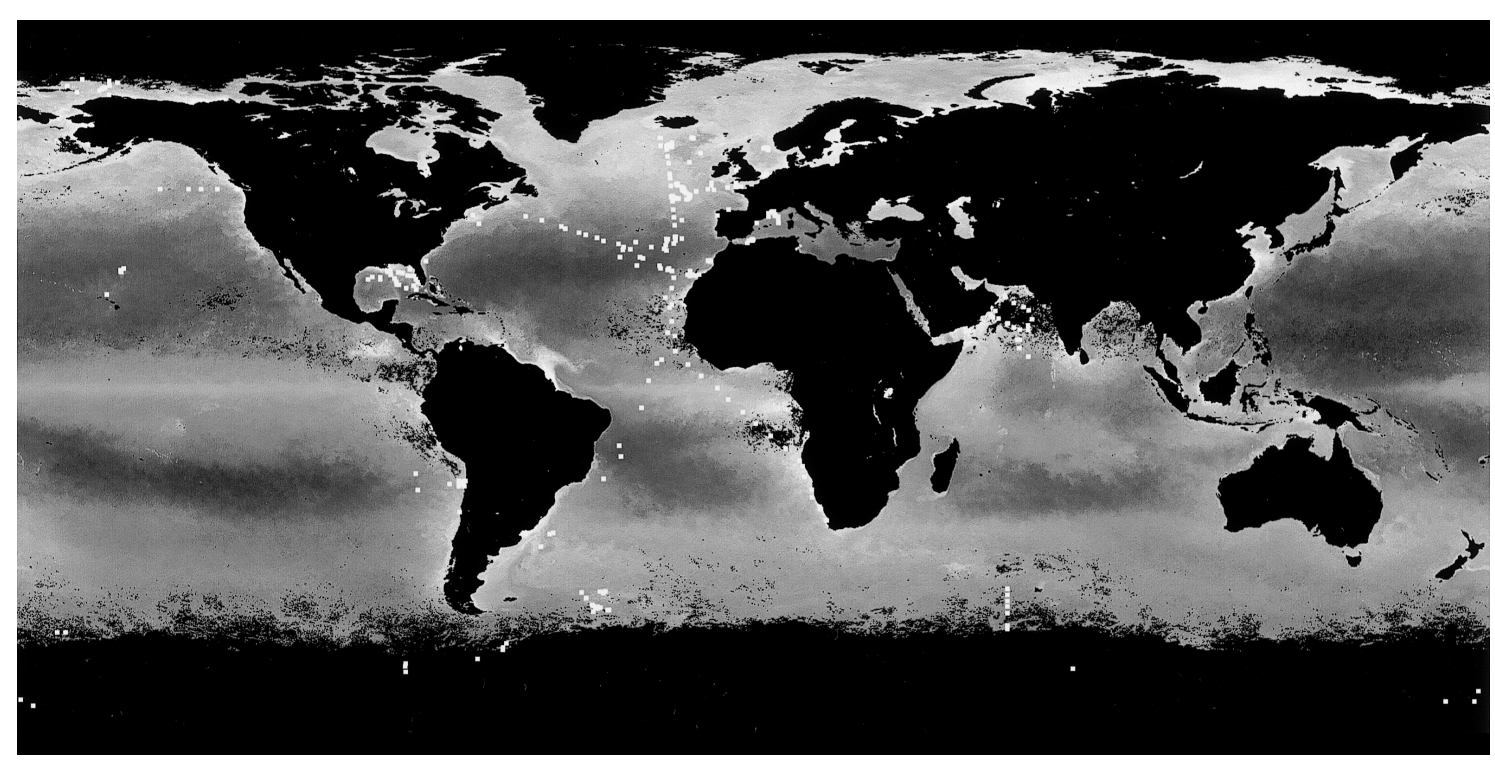

Figure 9.2 Global database of respiration measurements positioned on map of SeaWiFs ocean color.

et al. 2000; Dickson and Orchardo, 2001; Dickson et al. 2001; Gonzalez et al. 2001, 2002). Where possible the respiration data are supported by concurrent measurements of in situ temperature, chlorophyll $a$ concentration, bacterial abundance, particulate organic carbon, light attenuation, and gross production. Of the observations, $91 \%$ of the data are derived from Winkler oxygen titrations, $3 \%$ from oxygen consumption measured by oxygen electrode, $4 \%$ are "daily" respiration rates derived from ${ }^{18} \mathrm{O}_{2}$ (i.e. incorporating both "light" and "dark" respiration; Bender et al. 1999), and <2\% of the data are derived from ETS activity. Open-ocean observations account for $71 \%$ of the measurements; the remainder have been collected on the shelf $(<200 \mathrm{~m})$. Figure 9.2 highlights just how spatially restricted and depauperate the global database is.

The mean respiration rate of this complete volumetric dataset is $3.5 \pm 0.13 \mathrm{mmol} \mathrm{O}_{2} \mathrm{~m}^{-3} \mathrm{~d}^{-1}$ (mean \pm standard error, the standard deviation is 5.3 ; range of the mean is $\left.0.02-75 \mathrm{mmolO}_{2} \mathrm{~m}^{-3} \mathrm{~d}^{-1}\right)$, and of surface water $(<10 \mathrm{~m})$ alone, is $4.9 \pm 0.23 \mathrm{mmol} \mathrm{O}_{2} \mathrm{~m}^{-3} \mathrm{~d}^{-1}$. The mean surface water $(<10 \mathrm{~m})$ respiration rate measured in coastal areas is $7.4 \pm 0.54 \mathrm{mmol} \mathrm{O}_{2} \mathrm{~m}^{-3} \mathrm{~d}^{-1}(n=323$; range 0.1-75 $\left.\mathrm{mmol} \mathrm{O}_{2} \mathrm{~m}^{-3} \mathrm{~d}^{-1}\right)$, and the mean of surface water measurements made in open-ocean areas is $3.3 \pm 0.15 \mathrm{mmolO}_{2} \mathrm{~m}^{-3} \mathrm{~d}^{-1} \quad(n=502$; range 0.02-33.8 $\mathrm{mmol} \mathrm{O}_{2} \mathrm{~m}^{-2} \mathrm{~d}^{-1}$ ). Where respiration was measured at three or more depths we have calculated depth-integrated rates, to the depth of the deepest sample using a conventional trapezoid procedure. The integration depth varies from 10 to $150 \mathrm{~m}$ with a mean of $53 \mathrm{~m}$ and a median of $40 \mathrm{~m}$. Since respiration measurements have historically been made in support of gross production measurements, the deepest depth sampled in most cases is the $1 \%$ light depth rather than the mixed layer depth. The means for the whole depth integrated dataset $(n=229)$, the open-ocean dataset $(n=186)$, and the coastal/shelf seas dataset $(n=43)$ are $114 \pm 5.1,116 \pm 8.5$, and $107 \pm 11 \mathrm{mmol} \mathrm{O}_{2} \mathrm{~m}^{-2} \mathrm{~d}^{-1}$ (mean \pm standard error; standard deviation $\sim 100 \mathrm{mmol} \mathrm{O}_{2} \mathrm{~m}^{-2} \mathrm{~d}^{-1}$ ), respectively.

The respiration data have been assessed with respect to latitudinal and seasonal distribution and covariance with more frequently made measures of plankton biomass and activity. Figure 9.2 indicates the spatial distribution of the respiration data presented on a satellite image of ocean color. Such a portrayal of the data emphasizes the urgent need for more data (Jahnke and Craven 1995; Williams 2000). 


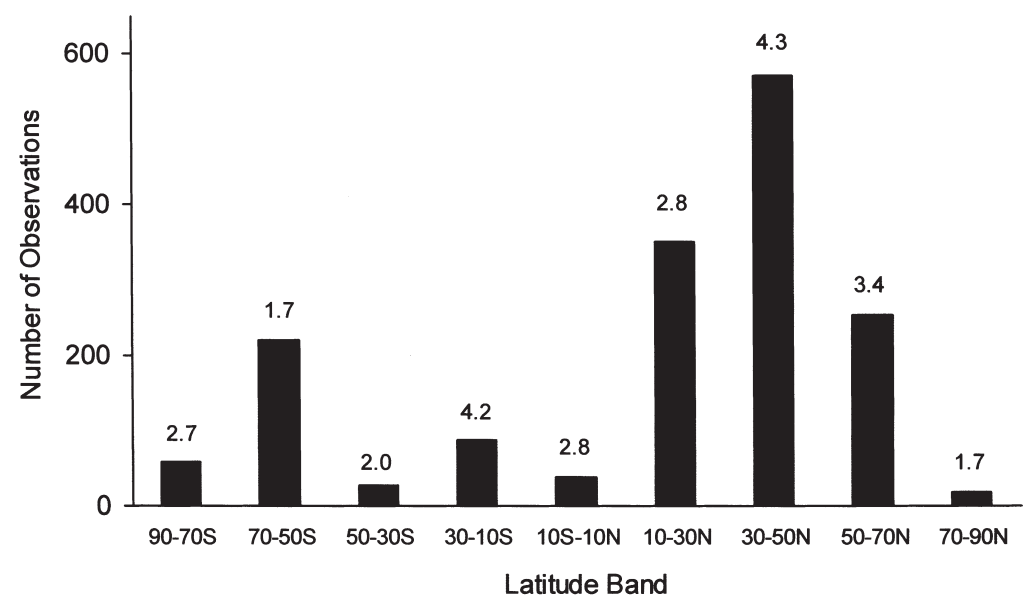

Figure 9.3 Latitudinal distribution of the number of observations of volumetric rates of community respiration. The mean rate for each latitude band $\left(\mathrm{mmol}_{2} \mathrm{~m}^{-3} \mathrm{~d}^{-1}\right)$ is shown above each histogram.

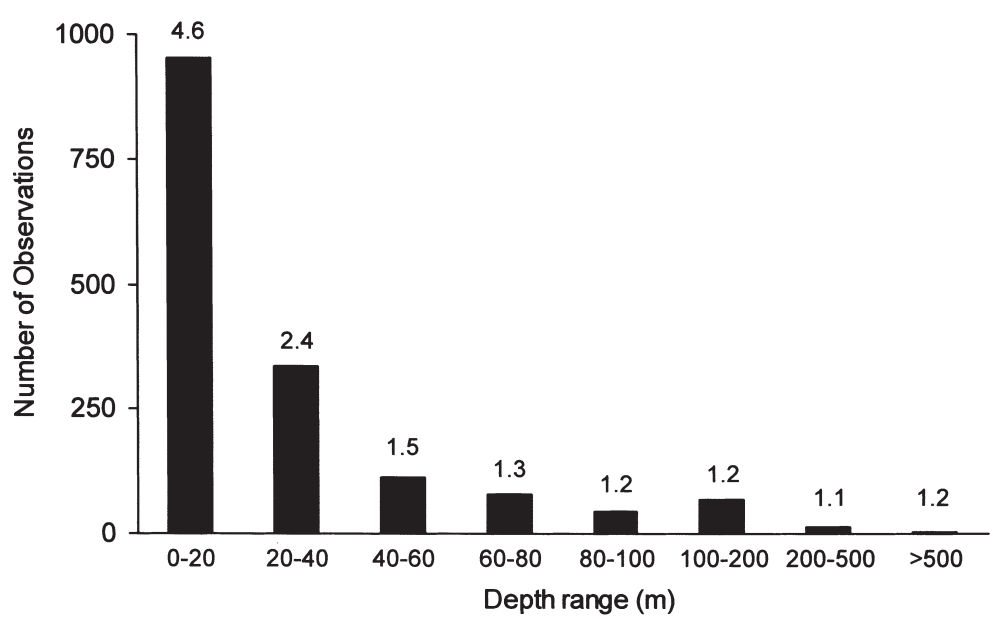

Figure 9.4 Depth distribution of the number of observations of volumetric rates of community respiration. The mean rate for each depth range $\left(\mathrm{mmol} \mathrm{O}_{2} \mathrm{~m}^{-3} \mathrm{~d}^{-1}\right)$ is shown above each histogram.

The frequency histogram of respiration versus latitude (Fig. 9.3) reveals that the greatest number of samples have been collected within the latitudinal band between $30^{\circ} \mathrm{N}$ and $50^{\circ} \mathrm{N}$ where the mean respiration rate is $4.3 \mathrm{mmol} \mathrm{O}_{2} \mathrm{~m}^{-3} \mathrm{~d}^{-1}$. As mentioned above, the majority of respiration measurements have been made within the euphotic zone. Less than 100 measurements of respiration ( $\sim 5 \%$ of the dataset) were collected below $100 \mathrm{~m}$ (Fig. 9.4). Interestingly, of the small number of measurements made, the mean rate is still relatively high ( $>1 \mathrm{mmol} \mathrm{O}_{2} \mathrm{~m}^{-3} \mathrm{~d}^{-1}$ ) and easily measurable with a $24 \mathrm{~h}$ oxygen incubation technique. Data are unevenly distributed throughout the year (Fig. 9.5). As might be expected, most of the measurements were collected during the temperate and austral spring. In the Northern Hemisphere the mean respiration rates for April, May, June and July, were $3.5,6.2,5.8$, and $8.9 \mathrm{mmol} \mathrm{O}_{2} \mathrm{~m}^{-3} \mathrm{~d}^{-1}$, respectively. The mean respiration rates for data collected during 


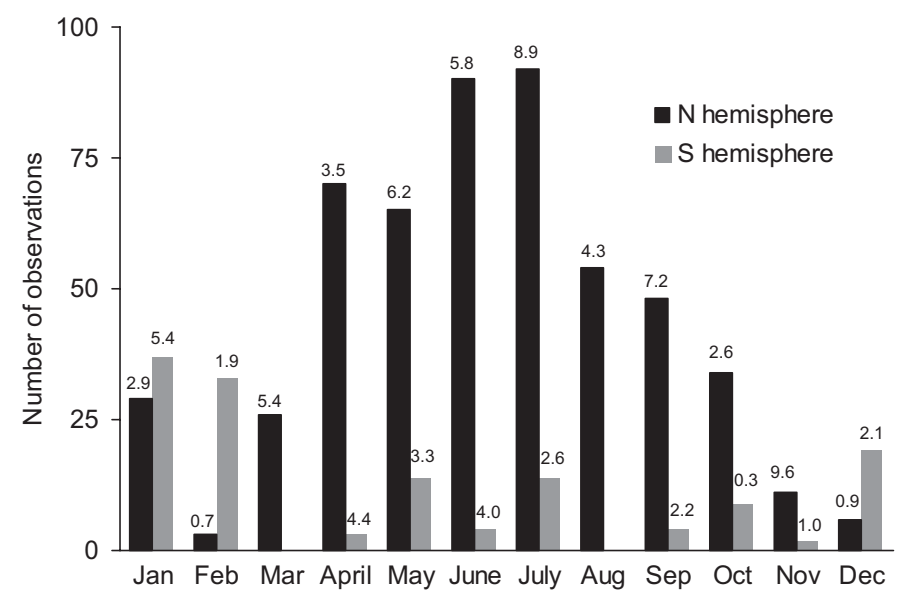

Figure 9.5 Seasonal distribution of the number of observations of volumetric rates of community respiration. The mean rate for each calendar month $\left(\mathrm{mmol} \mathrm{O}_{2} \mathrm{~m}^{-3} \mathrm{~d}^{-1}\right)$ is shown above each histogram.

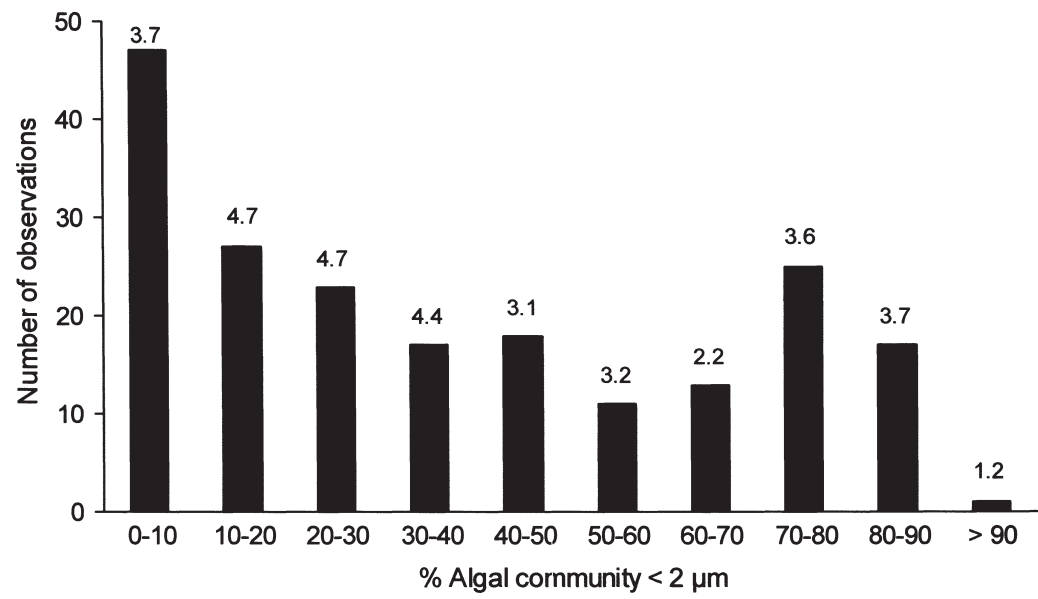

Figure 9.6 Distribution of the number of observations of volumetric rates of respiration with respect to the algal community size structure. The mean rate for each category $\left(\mathrm{mmol} \mathrm{O}_{2} \mathrm{~m}^{-3} \mathrm{~d}^{-1}\right)$ is shown above each histogram.

December, January, and February in the Southern Hemisphere are 2.1, 5.4, and $1.9 \mathrm{mmolO}_{2} \mathrm{~m}^{-3} \mathrm{~d}^{-1}$, respectively. High mean respiration rates measured in September and November in the Northern Hemisphere are biased by coastal studies undertaken at this time of the year.

A focus of research in the late 1980s and 1990s was the study of global carbon cycling and the role of phytoplankton in drawing down atmospheric carbon dioxide (JGOFS Science Plan). Hence, one expected bias in the respiration data is that the majority of the data were collected during diatom dominated spring blooms (Williams 1998). We have therefore analyzed a frequency histogram of respiration against a broad estimate of phytoplankton community structure-the percentage of total chlorophyll attributable to the smallest cells present (Fig. 9.6). Note that some authors have measured the fraction between $0.2-2 \mu \mathrm{m}$ as their smallest size band, while others have used $<1 \mu \mathrm{m}$. There 
does seem to be a bias towards data collected during larger cell dominated algal populations-with a smaller peak at populations, which have a large proportion (70-80\%) of smaller cells. This is possibly due to the inclusion of the three datasets from the Atlantic Meridional Transect program (AMT), which sample the picoautotroph dominated midocean gyres (Gonzalez et al. 2002; Robinson et al. $2002 a$ ). There is no clear pattern between the percentage of chlorophyll attributed to $<2 \mu \mathrm{m}$ cells and the magnitude of respiration.

\subsubsection{Analysis of the data}

The respiration data are biased with respect to time, place, community structure, and depth (see Figs 9.29.6). The dataset is particularly deficient in data from deeper water and for periods of the year of low photosynthetic activity. As a consequence the dataset is not comprehensive enough to allow the preparation of maps. In this respect, we are not at the stage that was reached by the ${ }^{14} \mathrm{C}$ community in 1968 , when it was possible to produce a realistic map of oceanic productivity (see discussion in Barber and Hilting 2002).

Relationships between respiration and chlorophyll, bacterial abundance, particulate organic carbon, and attenuation

As community respiration is determined by the activity of the algal, bacterial, and microzooplankton community present, one may expect that respiration would be correlated with the abundance or biomass of one or more of the components of the plankton community. Robinson et al. (2002a) found significant $(p<0.001)$ relationships between respiration and bacterial abundance, chlorophyll $a$, beam attenuation, and particulate organic carbon (POC) of samples collected along a $12000 \mathrm{~km}$ latitudinal transect of the Eastern Atlantic Ocean. Robinson et al. (2002b) combined these data with those collected during a study of a coccolithophore bloom in the North Sea, and similarly found significant relationships between respiration, and bacterial and microzooplankton biomass, POC, and chlorophyll $a$. Since these latter parameters are less time and labor intensive in their collection and analysis, these authors drew attention to their value as "predictors" of community respiration. Of the variance in respiration, $40-50 \%$ could be accounted for by the variation in bacterial biomass or POC. Using the larger database of respiration measurements collected for the present review we were curious of the predictive power of one or more of these single variable regression equations. Figure 9.7 shows weak relationships between respiration, chlorophyll $a$, POC, bacterial abundance, and attenuation with their associated major reduced axis regressions. Only $20-30 \%$ of the variance in respiration can be accounted for by the variation in one of these more routinely measured parameters. Unfortunately, the concurrent data are too sparse to probe this unexpected result. Of the 18 individual studies where respiration and chlorophyll are reported, in only $50 \%$ of cases is the $r^{2}$ of the relationship between respiration and chlorophyll $a$ greater than 0.3 . These nine studies tend to be in shelf seas with large ranges in chlorophyll $\left(0.2-50 \mathrm{mg} \mathrm{m}^{-3}\right)$ and respiration (1-53 $\left.\mathrm{mmol} \mathrm{O}_{2} \mathrm{~m}^{-3} \mathrm{~d}^{-1}\right)$. The relationship between respiration and chlorophyll $a$ does not appear to depend on autotrophic community structure, for example, within the subset of data where less than $50 \%$ of the total chlorophyll is attributed to cells $<2 \mu \mathrm{m}$ in diameter (i.e. communities dominated by larger cells) respiration and total chlorophyll were not correlated.

\section{Relationships between respiration and photosynthesis}

Assuming that the open ocean is essentially a closed system (and this is debated), then respiration will be principally fueled by photosynthetic production of organic material. The coupling between photosynthesis and respiration will be both physiological (in algae) but also trophic (in heterotrophs). In the former case, the coupling may be tight and on physiological rather than ecological timescales. The flow and recycling through the food web introduce time lags, so that the two processes of community photosynthesis and respiration become out of phase with one another-the latter trailing the former. Temporal studies in pelagic marine ecosystems on timescales that allow the examination of the phasing of the two processes are few (Blight et al. 1995; Serret et al. 


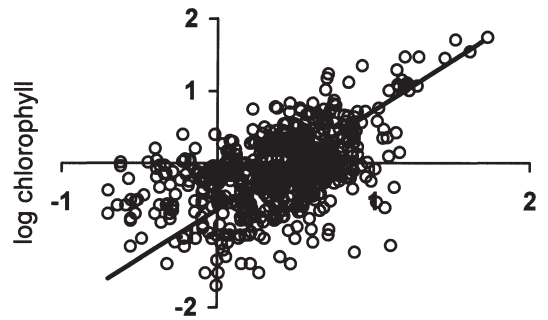

log respiration

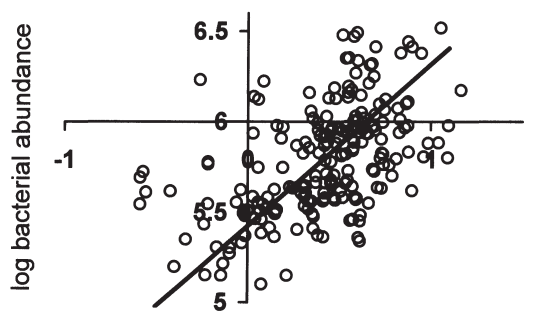

$\log$ respiration

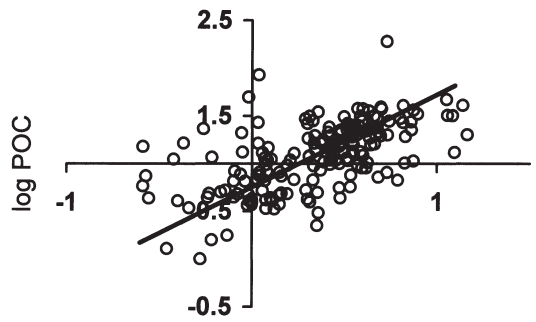

log respiration

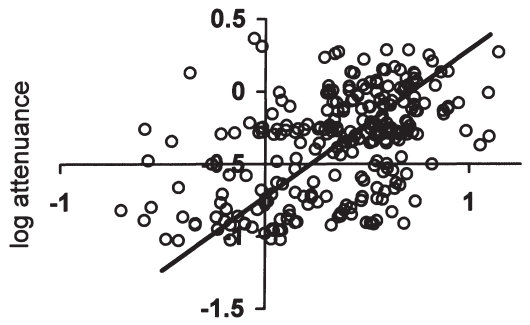

log respiration

Figure 9.7 $\log _{10}-\log _{10}$ plots of volumetric rates of respiration against chlorophyll $a, P O C$, bacterial abundance, and attenuance. Respiration

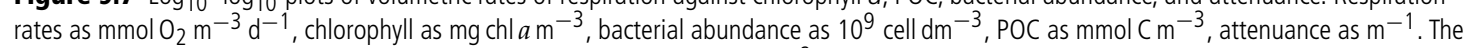
fitted lines are a Model 2 major reduced axis. Chlorophyll: $y=1.4 x+0.64 ; r^{2}=0.27, n=628$; bacterial abundance: $y=0.89 x+5.4$; $r^{2}=0.27, n=205 ;$ POC: $y=0.97 x-0.75 ; r^{2}=0.32, n=170 ;$ and attenuance: $y=1.01 x-0.72 ; r^{2}=0.22, n=260$.

1999; Williams 2000). In open-water situations, such studies are hindered by advective processes, hence mesocosms offer a more successful environment for such work. Figure 9.8 shows the results of studies in a series of replicate $11000 \mathrm{dm}^{3}$ mesocosms undertaken in a Norwegian Fjord. Figure 9.8(a) shows the simple time series. This illustrates the timescale of the phasing between photosynthesis and respiration. In this instance respiration trails photosynthesis by about 4 days. Figure 9.8(b) and (c) illustrate the swing from autotrophy to heterotrophy. Figure 9.8(d) shows the instantaneous relationship between photosynthesis and respiration. Two lines are fitted to the data-an ordinary least squares (OLS) and major reduced axis (MRA) regression. Both lines have slopes less than unity and this reflects the smaller variance in the respiration dataset as compared with concurrent measurements of photosynthesis. This almost certainly arises as a consequence of time delays stemming from the flow of organic production through the various trophic groups, thus dampening the fluctuations seen in primary production (see Aristeguí and Harrison 2002). The system being intermittently charged up by pulses of photosynthesis and discharged by a continuous leakage of organic material to respiration (Williams 1995). These concepts are useful in the interpretation of open field data.

The dataset of respiration, when compared to that of ${ }^{14} \mathrm{C}$-determined photosynthesis is small, about $1 \%$ of the photosynthetic observations (Williams and del Giorgio, Chapter 1). An obvious solution to this problem is to seek for relationships between respiration and photosynthesis. If such relationships can be found, then basin wide estimates of respiration could be derived from the massive database of photosynthesis, and potentially from models of photosynthesis.

In Fig. 9.9 we compare the frequency distributions of field observations of photosynthesis and respiration from our database. In the case of the volumetric rates, the respiration rates have a narrower distribution than the photosynthetic ratesconsistent with the capacitance effect of the food 
a) Time series of Respiration and Photosynthesis

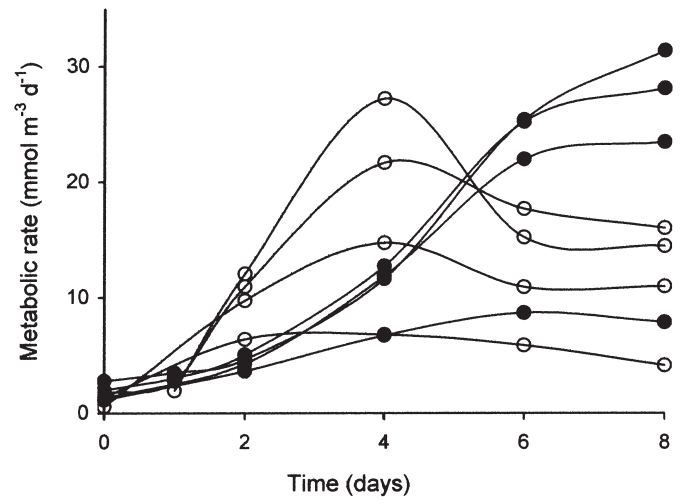

c) Time development of P/R ratio

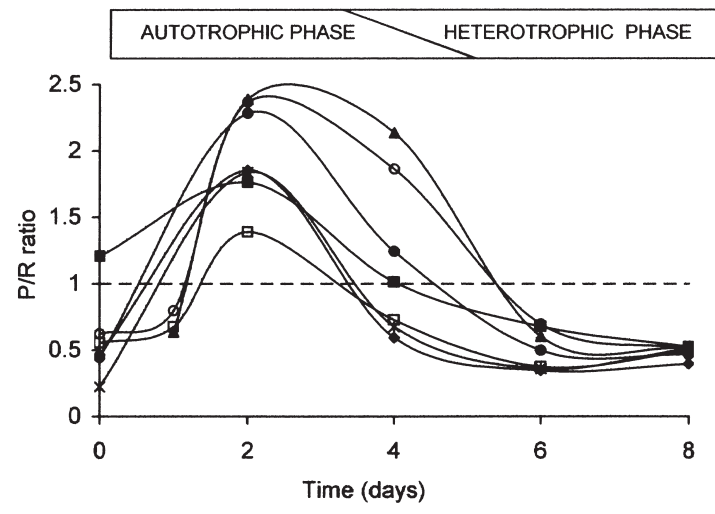

b) Phase Plot of Respiration and Photosynthesis

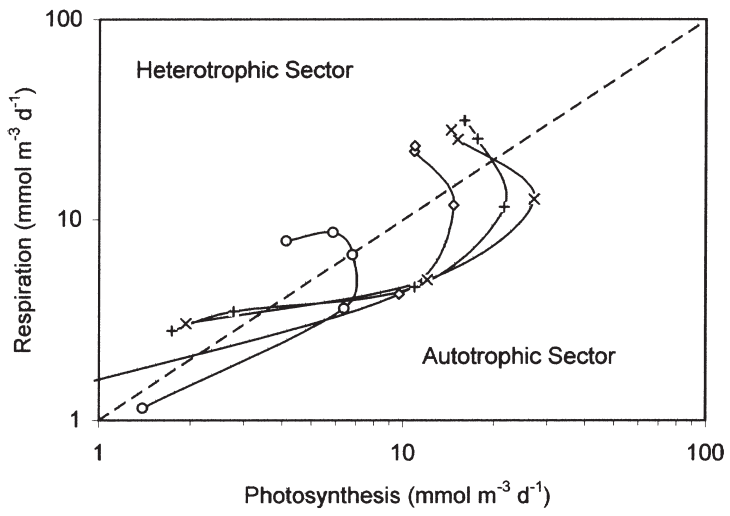

d) Log-log Plots of Respiration versus Photosynthesis

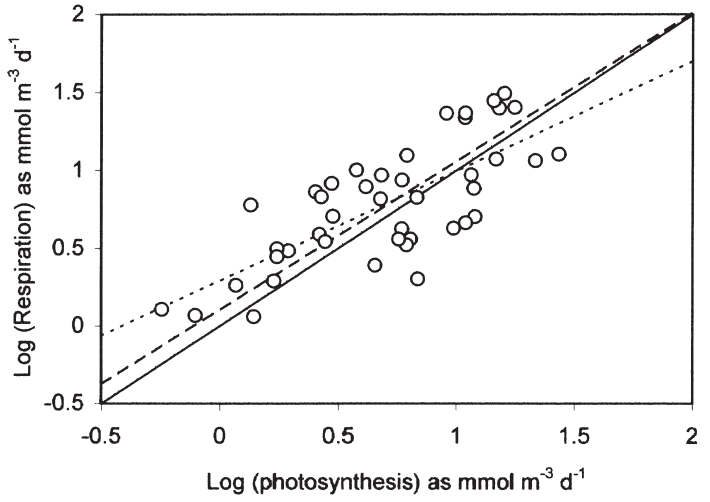

Figure 9.8 Analysis of time series of photosynthesis and respiration followed over 8 days in a series of $11 \mathrm{~m}^{3}$ mesocosms. (a) Time-series plot of photosynthetic rate (open circles) and respiration (filled circles), (b) phase plots of photosynthesis and respiration, (c) time development of $P / R$ ratio, and (d) $\log _{10}-\log _{10}$ plots of photosynthesis and respiration. The dotted line shows an OLS fit, the dashed line an MRA fit and the solid is the $P=R$ line.

web on respiration. The frequency distribution of the depth-integrated rates of respiration is skewed at the upper end-a product of a small number (5-6 profiles) of very high respiration values. For this reason we have worked with log-normalized rates, as most of the line-fitting procedures we use require a normal distribution of values within the dataset.

The first attempt to analyze a wide range of environments for the relationship between photosynthesis and respiration was made by del Giorgio et al.(1997). They found that respiration was scaled to photosynthesis with an exponent less than unity. Duarte and Agusti (1998) using a larger dataset
(280 observations) confirmed the findings of del Giorgio et al. They found that community respiration was scaled as the approximate two-thirds power of photosynthesis, the correlation between the two parameters was high $\left(r^{2}=0.42\right)$. The slope of the log-log relationship for the open ocean was somewhat lower (0.5). We have repeated this analysis (see Fig. 9.10) on the larger database now available to us (957 paired observations of volumetric rates of oxygen flux derived gross production and respiration). The correlation is much the same $\left(r^{2}=0.43\right)$, but the slope is reduced to 0.4 , this is most likely due to the addition of datasets from coastal regions and low latitudes (Holligan et al. 
(a)

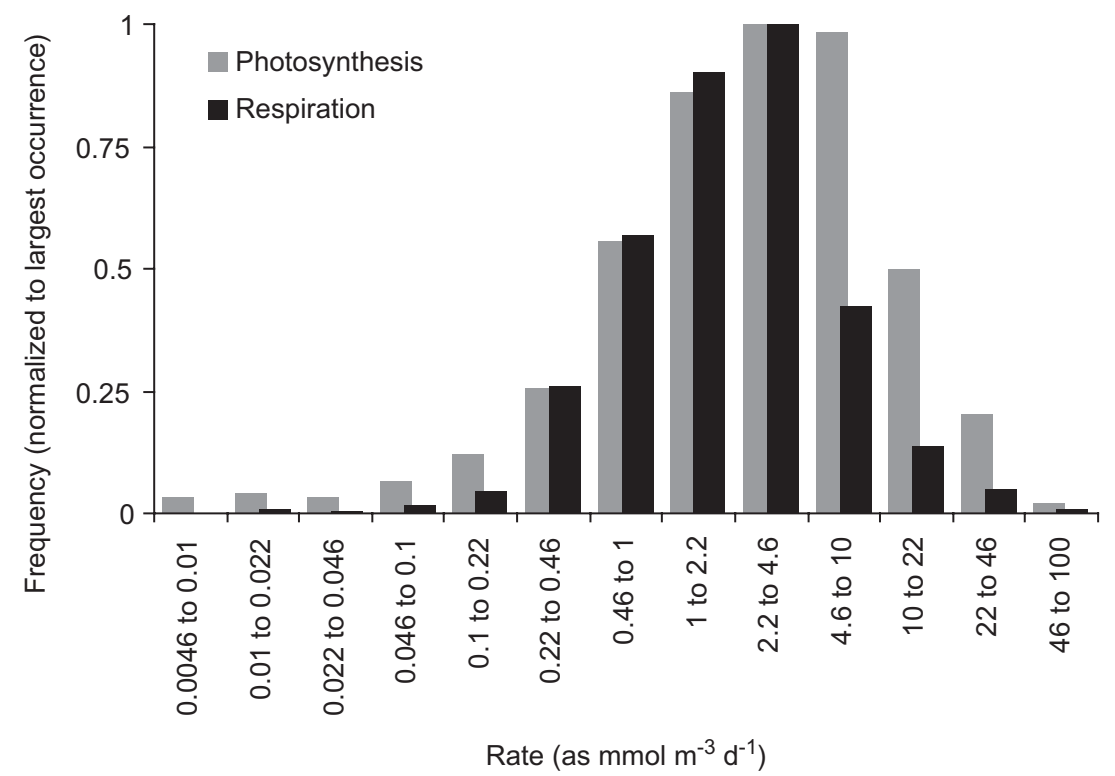

(b)

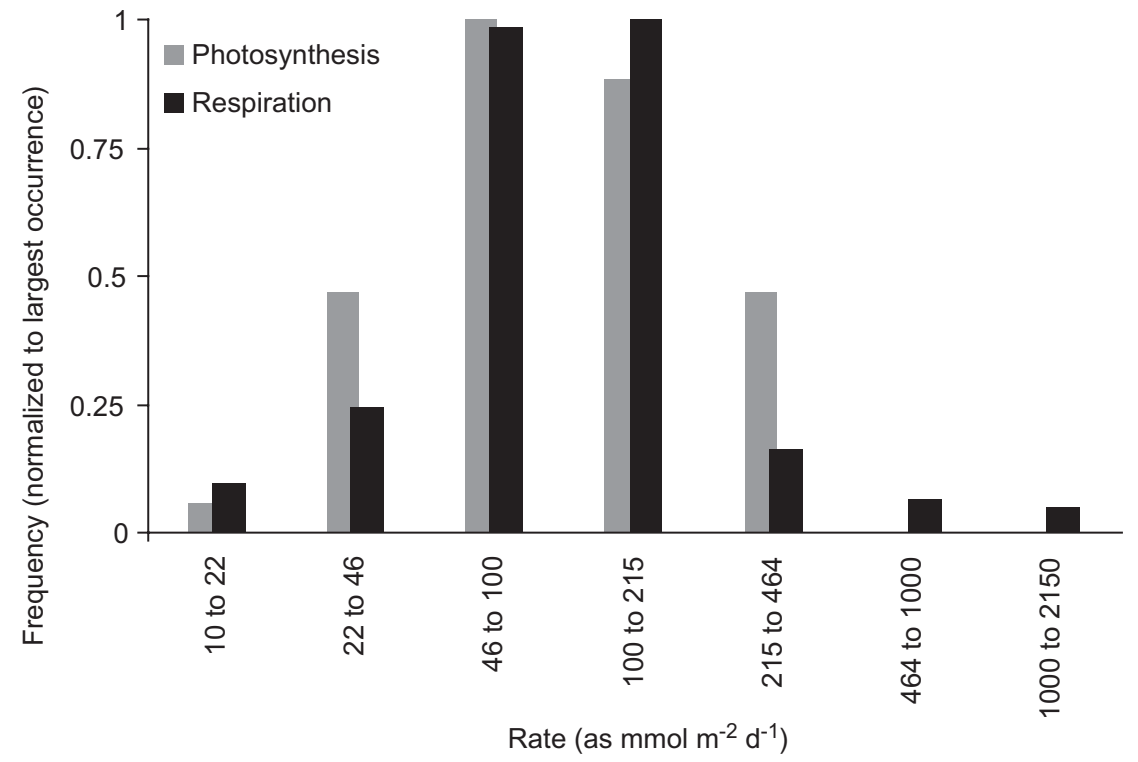

Figure 9.9 Frequency distribution of photosynthetic and respiration rates. The data has been sorted into three bins per decade and are normalized to the largest sample. Frequency distributions of (a) volumetric rates and (b) depth-integrated rates are shown. 


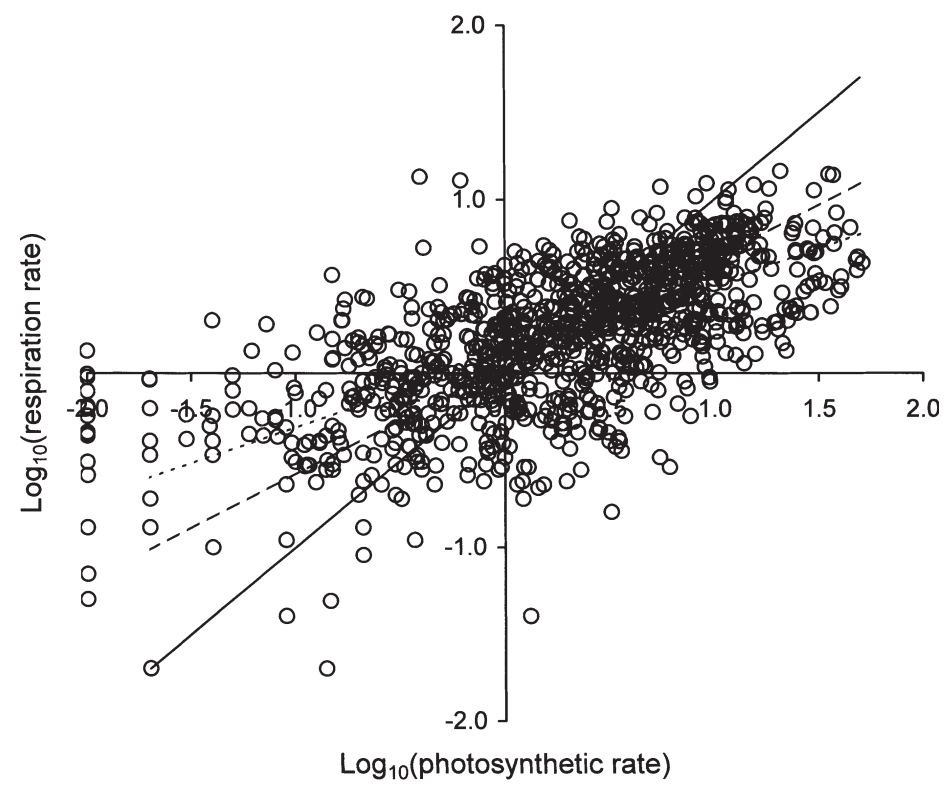

Figure $9.10 \log _{10}-\log _{10}$ plot of volumetric respiration and photosynthesis. Rates as mmol $\mathrm{m}^{-3} \mathrm{~d}^{-1}$. The dotted line shows an OLS fit $(y=0.412 x+0.1)$, the dashed line an MRA fit $(y=0.62 x+0.04)$, and the solid is the $P=R$ line. The $R^{2}$ of the log-normalized data was 0.44 .

1984; Arístegui et al. 1996; Robinson et al. 1999; Robinson unpublished data) where low $P / R$ ratios have been recorded. The variance of photosynthesis (expressed as the standard deviation) is greater than respiration $(0.72$ versus 0.42$)$, which is the basis of the low slope. Both del Giorgio et al. (1997) and Duarte and Agusti (1998) noted that at low photosynthetic rates, the rates of respiration exceeded those of photosynthesis. Based on their derived relationship between photosynthesis and respiration, and the estimated primary production in each biogeochemical province in the ocean, Duarte and Agusti (1998) concluded that " $80 \%$ of the ocean's surface are expected to be heterotrophic...," supported by a net autotrophy in the remaining $20 \%$ of the ocean. This was a controversial conclusion. The two matters of contention were the timescale of the net heterotrophy (whether permanent or transient) and the supply mechanism of the carbon required to support the net heterotrophy.

With volumetric rates one encounters a separation of photosynthesis and respiration, in time (as illustrated in Fig. 9.8) but also in space (depth) This complicates the elucidation of the ecological relationship between photosynthesis and respiration. Williams (1998) suggested that the depthintegrated rates would overcome the second of these two effects. The penalty is a fivefold reduction in the number of paired photosynthesis and respiration observations from 957 volumetric rates to about 200 depth-integrated rates. The depth-integrated rates are analyzed in Fig. 9.11.

There are important differences between the relationships between photosynthesis and respiration in the volumetric and depth-integrated datasets. The principal difference is that in the log normalized plots, most $(72 \%)$ of the correlation between photosynthesis and respiration seen in the volumetric rates is lost in the depth-integrated rates. The reason for such a major loss in correlation is not wholly clear and critical in understanding its significance. It could be that the main basis of the relatively high correlation in the volumetric plots came from internal correlation in individual profiles-were this the case, then the relationships obtained from analyses of volumetric plots would have little capability to predict regional differences. A further reason could be sampling bias, either with respect to depth 


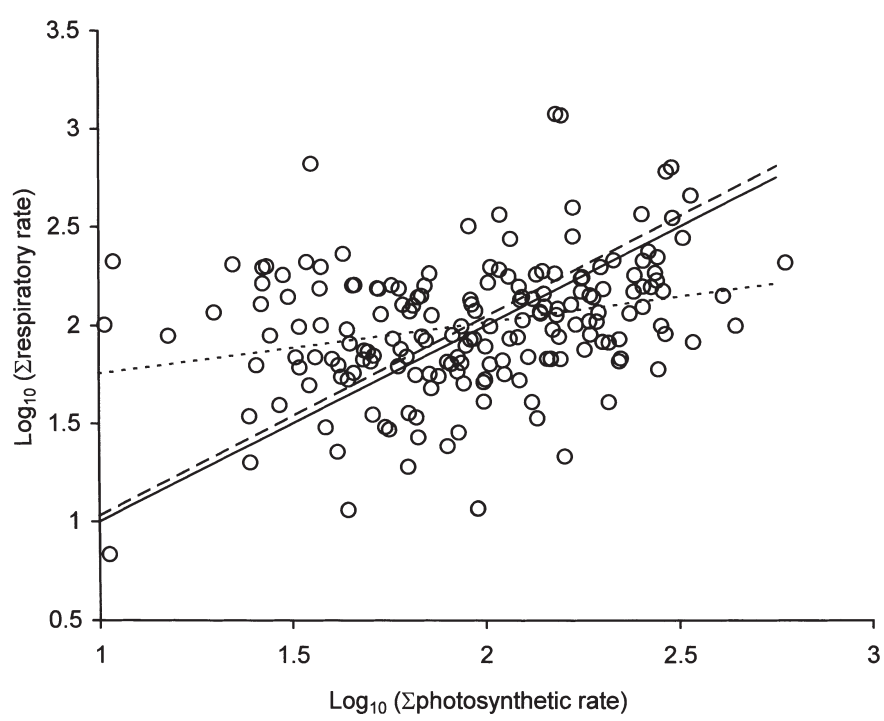

Figure 9.11 $\log _{10}-\log _{10}$ plot of depth-integrated respiration and photosynthesis. Rates as mmol $\mathrm{m}^{-2} \mathrm{~d}^{-1}$. The dotted line shows an OLS fit $(y=0.26 x+1.5)$, the dashed line an MRA fit $(R=1.0 x+0.01)$, and the solid is the $P=R$ line. The $R^{2}$ of the log-normalized data was 0.07 .

(Fig. 9.4), or community structure (Fig. 9.6) as proposed by Serret et al. (2001). Due to the different depth distributions of photosynthesis and respiration, the disparity between the variances in the photosynthetic and respiration rates, seen in the volumetric plots is lost in the depth-integrated plots (standard deviation respiration $=0.34$; standard deviation photosynthesis $=0.33$ ). This implies that most of the nonlinear scaling between volumetric rates of photosynthesis and respiration comes from the differences in the depth distribution of these two properties.

The low correlation $\left(r^{2}=0.13\right)$ between depthintegrated photosynthesis and respiration, suggests that areal photosynthesis is a weak predictor of areal respiration. In many respects it is a disappointing result but was the prediction of Williams and Bowers (1999) and the conclusion of Serret et al. $(2001,2002)$. The conclusion does not sit comfortably with the proposition, at the beginning of the section, that respiration is principally fueled by autochthonous photosynthesis. This may be due to a number of factors: for example, the systems are not closed, or there are temporal offsets between respiration and photosynthesis.
The argument has been made (e.g. Duarte and Agusti 1998; Serret et al. 2002) that there are differences between the balance of photosynthesis and respiration in different biogeochemical zones, thus simply working from global averages is inappropriate. Longhurst (1998) identified 55 biogeochemical zones in the oceans, these would represent the most logical framework into which to bin the present data, however with only $\sim 200$ depthintegrated observations this degree of resolution is presently far too fine. As an alternative, in order to attempt an analysis, we have grouped the data in $10^{\circ}$ of latitude, this gives 17 bins. Even with such a coarse separation the distribution is exceedingly patchy and does not in any way match the areas of ocean within each latitudinal band (Fig. 9.12). The Pacific and the Indian oceans are particularly poorly sampled with no measurements south of $10^{\circ} \mathrm{N}$ and above $30^{\circ} \mathrm{N}$. Most of the measurements lie between $20-50^{\circ} \mathrm{N}$ in the Atlantic. In the Atlantic the estimates for the latitudes greater than $20^{\circ} \mathrm{N}$ show some degree of consistency (see Fig. 9.13), with photosynthesis around $120 \mathrm{mmolO}_{2} \mathrm{~m}^{-2} \mathrm{~d}^{-1}$ and respiration close to $95 \mathrm{mmol} \mathrm{O}_{2} \mathrm{~m}^{-2} \mathrm{~d}^{-1}$. When the variance in the dataset is considered the difference 


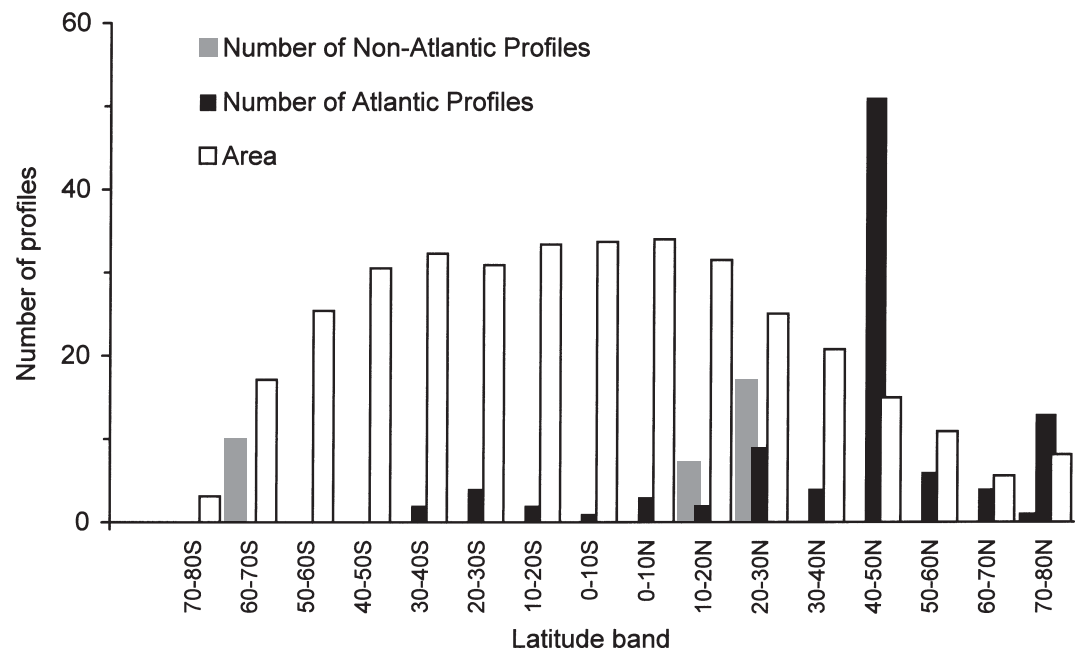

Figure 9.12 Comparison of the latitudinal distribution of depth-integrated rates of community respiration in the Atlantic and other oceans. The data is divided into Atlantic and non-Atlantic Ocean and presented alongside the area (as $10^{12} \mathrm{~m}^{2}$ ) of each of the latitudinal bands of ocean.

of $+25 \mathrm{mmolO}_{2} \mathrm{~m}^{-2} \mathrm{~d}^{-1}$ between photosynthesis and respiration is just significant. The rates reported for the latitudes between $20^{\circ} \mathrm{N}$ and $20^{\circ} \mathrm{S}$ are higher (photosynthesis $168 \mathrm{mmol} \mathrm{O}_{2} \mathrm{~m}^{-2} \mathrm{~d}^{-1}$; respiration $230 \mathrm{mmolO}_{2} \mathrm{~m}^{-2} \mathrm{~d}^{-1}$ ), the number of samples is however low and the variance considerable, leaving the difference $\left(-62 \mathrm{mmolO}_{2} \mathrm{~m}^{-2} \mathrm{~d}^{-1}\right)$ of borderline significance.

Whereas the differences between respiration and photosynthesis within the current dataset may be on the edge of significance, the pattern of negative net community production on the eastern periphery of the North Atlantic Gyre is a repeated observation (Duarte and Agusti 1998; Duarte et al. 2001; Robinson et al. 2002a; Serret et al. 2001, 2002) and in contradiction with geochemical studies of biogenic $\left(\mathrm{O}_{2}\right.$ and $\mathrm{CO}_{2}$ ) gas exchange (Jenkins and Goldman 1985; Keeling and Shertz 1992; Emerson et al. 1997, 2002). Several suggestions have been made to account for this anomaly, none of which have as yet been fully proved or refuted. Sampling methodologies could be underestimating gross production, second the area could be fueled by a carbon source from distant previously net productive areas, finally local temporal separation of photosynthesis from respiration could alias the results. The second explanation was put forward by Harrison et al. (2001) to account for the net heterotrophic areas in the eastern subtropical Atlantic where they argued that the subsidy was derived from filaments advecting offshore from productive areas.

There are very few seasonal studies in low productivity areas where net heterotrophy has been reported-hence one could be observing a net heterotrophic phase following an unobserved net autotrophic one (Serret et al. 1999). This has recently been remedied with a 13-month study at the HOT site (station ALOHA at $22^{\circ} 45^{\prime} \mathrm{N}$ and $158^{\circ} 00^{\prime} \mathrm{W}$ ) in the subtropical Pacific gyre (Williams et al. 2004). The annual totals (photosynthesis $22 \mathrm{molO}_{2} \mathrm{~m}^{-2} \mathrm{a}^{-1}$; respiration $31 \mathrm{molO}_{2} \mathrm{~m}^{-2} \mathrm{a}^{-1}$ ) give a deficit of $9 \pm 1.6 \mathrm{~mol} \mathrm{O}_{2} \mathrm{~m}^{-2} \mathrm{a}^{-1}$, which is significant and begs an explanation. In this case the proposition of allochthonous carbon sources is not compelling, as the areas in question are physically isolated. The gradients of dissolved organic carbon have been measured and they are in the opposite direction (Abell et al. 2000). The scale of the difference and the lack of any period of protracted seasonal accumulation of organic material exclude long term out of phase relationships between photosynthesis and respiration. The explanation favored by Williams et al. (2004) is based on intermittency of photosynthesis; the argument (Karl et al. 2003) being that there 
a) Latitudinal Averages

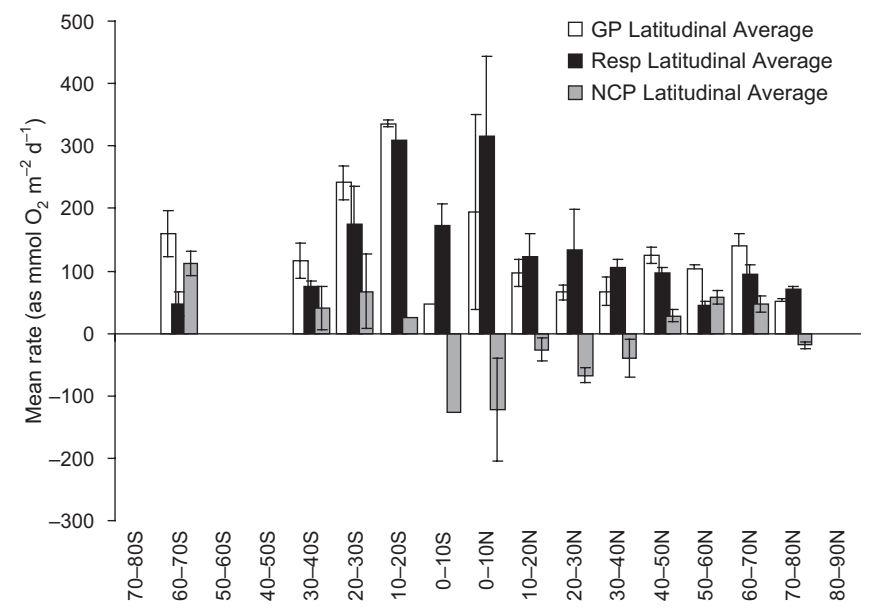

b) Latitudinal Totals

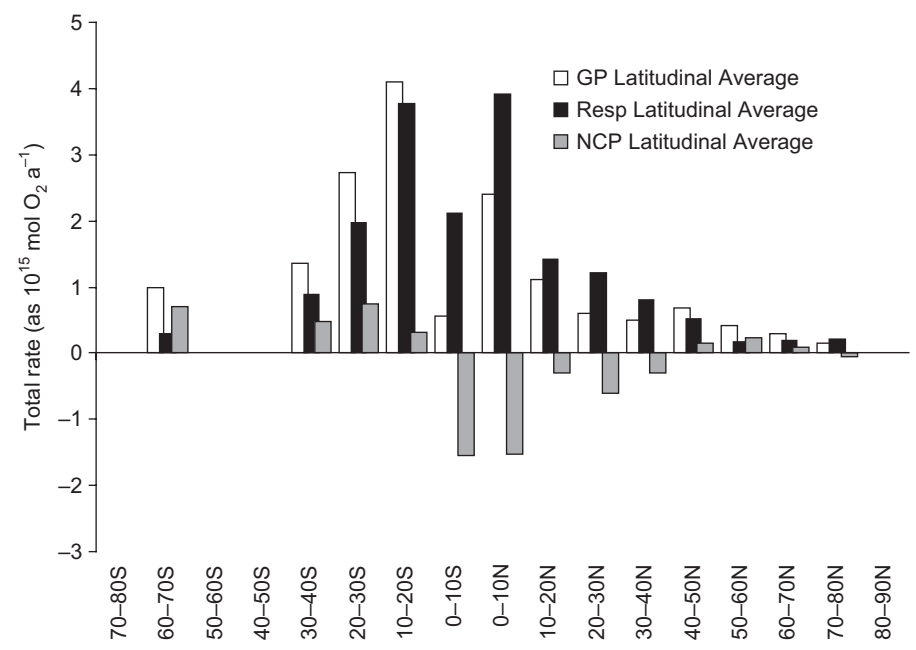

Figure 9.13 Comparison of the latitudinal distribution of depth-integrated rates of community respiration, net community production, and gross production. (a) the geometric means for $10^{\circ}$ latitude bands, the error bars represent the standard error for each band; (b) the total rates for each latitude band where data exists, calculated from the data in Fig. 9.12(a) and the oceanic area for each latitude band. The production values are concurrent $\mathrm{O}_{2}$-derived rates of gross and net community production.

are short intensive bursts of photosynthesis, which charge up the organic reservoir, which is then slowly and steadily discharged by respiration. The evidence for this comes from long-term continuous in situ observations of dissolved oxygen in the euphotic zone, which show periods of rapid accumulation of biologically produced oxygen. The explanation has an interesting and provocative corollarythat because of its better integrating properties, respiration may be a superior determinant of timeintegrated production than the measurement of photosynthesis itself. Whereas these explanations are the best we can currently offer; one inevitably asks why our sampling protocols have persistently 
missed these pulses and always made measurements during the periods of deficit. Without doubt we have much to learn about these systems and a great deal more work to do before we can expect an understanding of how they function.

\subsection{Distribution of respiration within the planktonic community}

When we consider the distribution of respiration within the community, we implicitly address two quite separate questions. The first is the distribution of respiration between the autotrophic and the heterotrophic communities; autotrophic respiration being that part of gross primary production (photosynthesis) not available to the rest of the community. The second question is the distribution of respiration within the heterotrophic component of the plankton-this provides insight into ecosystem functioning.

As there is no accepted procedure for blocking the metabolism of different sectors of the plankton with selective inhibitors, alternative ways of apportioning respiration within the planktonic community have had to be devised. They fall into five categories:

1. Calculations of the distribution of respiration from either observations of biomass or from algorithms of biomass distribution.

2. Measurements of the size distribution of respiration from which the respiration of organism groups may be inferred.

3. Derivation of respiration rates from measured or estimated rates of production, and growth efficiencies.

4. Determination of algal respiration as the difference between gross production and ${ }^{14} \mathrm{C}$ derived net primary production.

5. Derivation of respiration rates for various trophic groups from plankton food web models.

\subsubsection{Calculations from biomass}

Calculations from observations of biomass

Whereas there are a number of datasets for the biomass of particular plankton groups there are few comprehensive studies-in part due to the time and skill required to make a full analysis of biomass. No study, to our knowledge, contains estimates for all the major components of the food web (bacteria, protozoa, algae, and larval and adult zooplankton), so the apportionment of the relative contribution to metabolism will be incomplete. Clearly, if a class is omitted, then the contribution of the groups reported will be overestimated. The problem of ascribing rates to groups across the full size spectrum of the plankton is nontrivial. It is tempting to search for universal allometric relationships. In the case of the algae it seems possible to constrain biomass-related respiration reasonably well (Langdon 1993). Metazoa and protozoa would appear to have a sufficiently stable respiratory metabolism that a single allometric equation may be acceptable (see Fenchel, Chapter 4, Section 4.3), however one runs into major difficulties with the bacteria.

Table 9.2 contains a summary of reported calculations of respiration for various trophic groupings, expressed as a percentage of the sum of the reported rates. By far the most comprehensive study was that of Williams (1982) who used the data from the CEPEX study. This comprised data on bacteria, 3 categories of protozoa, 9 categories of algae, and some 44 categories of zooplankton, spanning the adults and all the larval stages. These observations were made on a large $\left(1300 \mathrm{~m}^{3}\right)$ mesocosm at 2- or 3 -day intervals over a 2 -month period. The data in the table show broad agreement between the various estimates of the contribution of different trophic groups to overall respiration, with bacteria comprising $12-58 \%$, the protozoa a further $11-36 \%$, the algae 8-70\%, and the larvae and adult zooplankton 3-9\%.

The CEPEX dataset analyzed by Williams was sufficiently extensive (it spanned $3 \frac{1}{2}$ orders of magnitude in the size of the organisms studied) that a size distribution of metabolism could be constructed. This is shown in Fig. 9.14, along with projections of respiration made from generalizations of biomass distribution. In its broad features it accords very well with observations of size-fractionated respiration and the projections from theoretical biomass profiles, the main discrepancy being in the $1-3 \mu \mathrm{m}$ size range. No organisms of that size were logged in the CEPEX study, probably not because they 


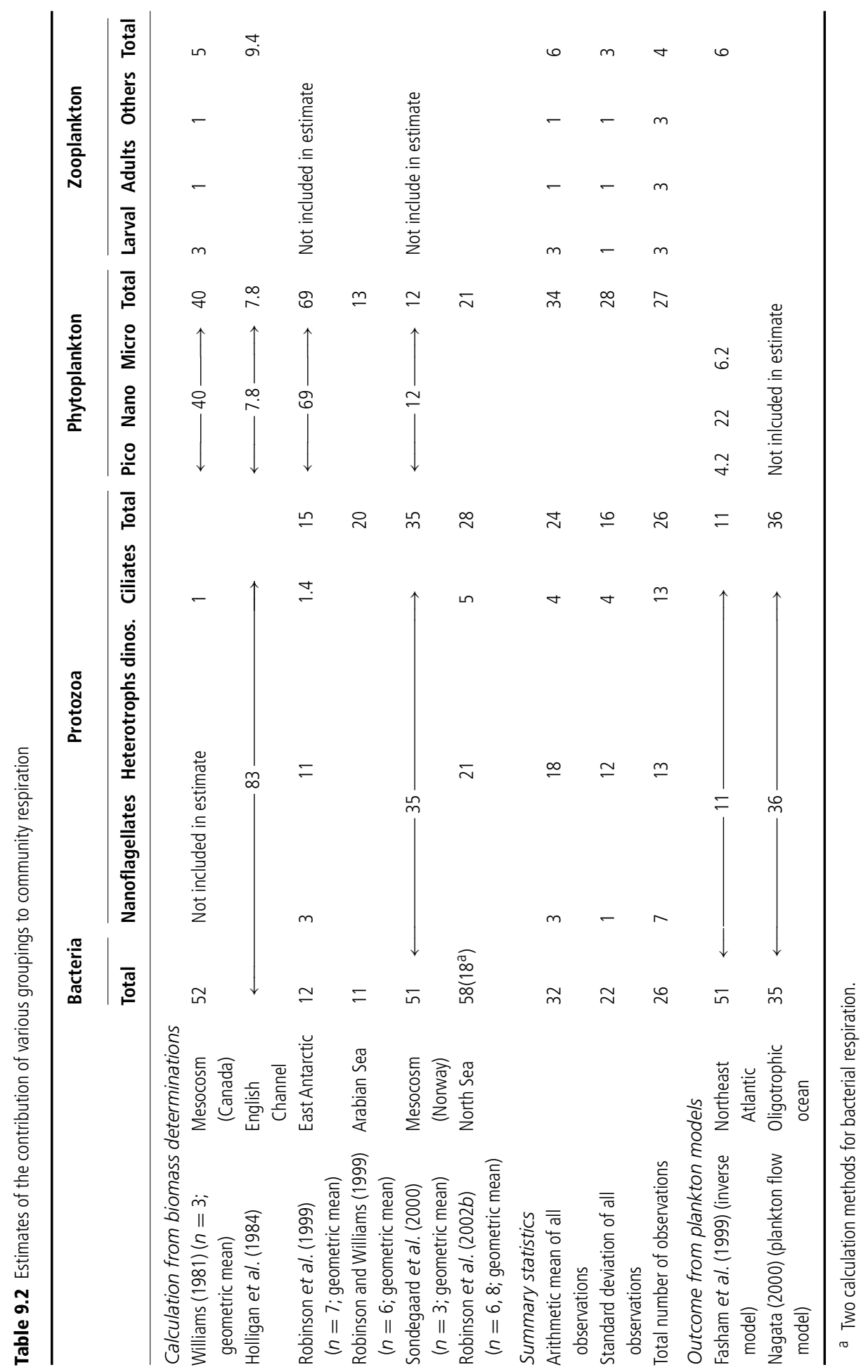

"chap09" - 2004/11/8 — page 167 — \#21 


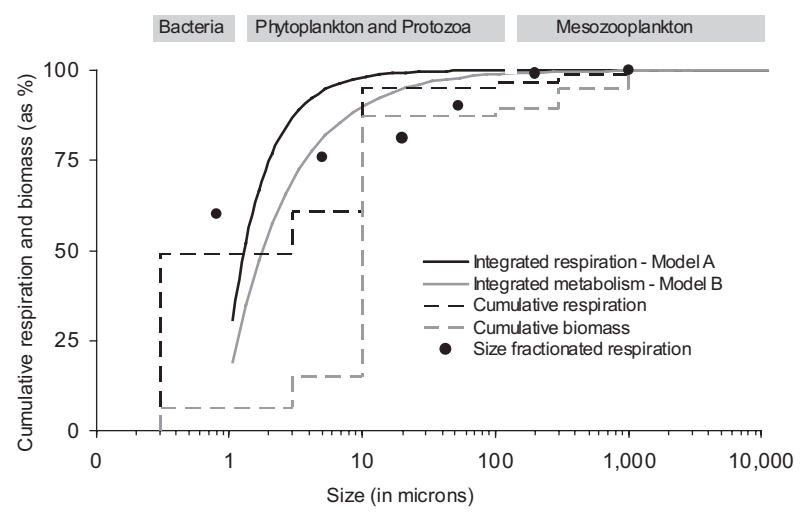

Figure 9.14 Size distribution of observed biomass and calculated and observed cumulative respiration. Integrated metabolism, Model A based on Platt and Denman (1977), Model B based on Sheldon et al. (1972). See Box 9.1 for basis of calculation. Cumulative and size-fractionated respiration and biomass taken from Williams (1982). were absent but that the skills were not available to recognize and enumerate them.

There is one caution with the data derived from field observations generally. As discussed earlier the sampling in many cases is biased to the productive part of the plankton cycle, this would put a bias to the data toward high algal contributions to overall community respiration.

\section{Calculations from generalized biomass profiles}

Generalized continuous biomass profiles of the plankton have been derived from field observations (Sheldon et al. 1972) and from theory based on an idealized food chain (Platt and Denman 1978). Both of these studies were evolved prior to the modern understanding of the microbial food web however, it would appear that they give a fair account of the modern view of the size of microbial biomass and metabolism.

Sheldon et al. (1972) concluded that the biomass profile was flat within logarithmic size classes. Platt and Denman (1978) found a decreasing biomass with increasing size, the slope being -0.22 (the broad structure of Platt and Denman's derivation is given in Box 9.1). These biomass/size distributions can be combined with equations of respiration versus size to produce size distributions of respiration. In general they show the same features, the size classes below $10 \mu \mathrm{m}$ account for more than $95 \%$ of the respiration; the size classes from 30 to $10000 \mu \mathrm{m}$ accounting for less than $1 \%$ of the total. A similar analysis was made by Platt et al. (1984) who also highlighted the importance of microbial metabolism.

\subsubsection{Experimental determination of the size distribution of respiration}

In lieu of selective inhibitors to block particular sectors of the plankton, size-fractionation filtration procedures have been used to progressively remove components of the plankton size spectrum-with respiration measurements being made on the various filtrates. This was used initially in studies of the size distribution of photosynthesis and was applied subsequently by Williams (1981) to establish the scale of bacterial respiration in relation to the whole community. The approach has a number of limitations: it cannot, for example, resolve between different functional groupings occupying the same size category. They may be inferred with a degree of certainty in the case of the extreme end-members, that is, bacteria $(<1 \mu \mathrm{m})$ or the mesozooplankton $(>100 \mu \mathrm{m})$, as they dominate their class sizes. Intermediate size classes will contain both heterotrophs (mainly protozoa) and autotrophs in variable proportions. There are also problems with attached organisms being included in largersize classes and the increase in prey consequent upon the removal of its predator. These cautions must be taken as constraints when interpreting the data. Time-series studies of size-fractionated samples and comparison of the size-fractionated respiration rates with those of the whole community can act as indicators of the scale of the constraint. The 


\section{Box 9.1 Theoretical calculation of biomass and respiration size distribution}

A general theory of size distribution within the plankton was derived by Platt and Denman (1977). It divides the size spectrum into a number of logarithmically increasing steps, either decades or octaves, and seeks to relate the biomass within a bandwidth to weight of the size class using an equation of the form:

$$
b_{w} / b_{0}=\left(w / w_{0}\right)^{\alpha}
$$

where:

$b_{w}$ is the total biomass within a bandwidth; $w$ is the characteristic weight of the size class; $\alpha$ is an allometric scaling constant; and

$b_{0}$ and $w_{0}$ are values for one particular size class, which is used to fix the relationship.

Assuming a unidirectional flow and Fenchel's (1974) empirical equations for the weight dependence of turnover $\left(\tau_{w}=A w^{\chi}\right)$ and respiration $\left(R_{w}=B w^{\gamma}\right)$, where $A, B$, $\chi$ and $\gamma$ are constants, one arrives at a solution for the size distribution for biomass equation (1) as:

$$
b_{w} / b_{0}=\left(w / w_{0}\right)^{-0.22}
$$

The value for $\alpha$ of -0.22 in equation (2) comes from the constants $A, B$, and Fenchel's observation that $\chi+\gamma \approx 1$

Equation (2) may be rearranged as:

$$
\begin{aligned}
& w / w_{0}=\left(b_{w} / b_{0}\right)^{-1 / 0.22} \\
& w=w_{0}\left(b_{w} / b_{0}\right)^{-1 / 0.22}
\end{aligned}
$$

Equation (4) can then be embedded into an overall allometric cell mass versus respiration equation $\left(R_{W}=B W^{\gamma}\right)$, such that:

$$
R_{w}=B w_{0}^{\gamma}\left(b_{w} / b_{0}\right)^{-\gamma / 0.22},
$$

where characteristically $\gamma$ has a value in the region of -0.3 .

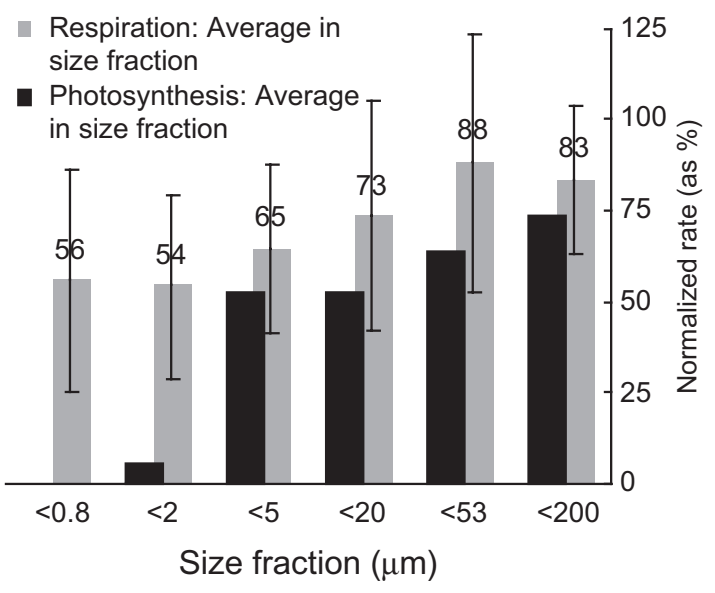

Figure 9.15 Rates of respiration and photosynthesis in size fractions. The rates are normalized against that of the unfractionated sample. Compiled from 62 sets of observations. Error bars are the standard errors.

size distribution of respiration from several studies (Harrison 1986; Griffith et al. 1990; Blight et al. 1995; Boyd et al. 1995; Robinson et al. 1999) is summarized in Fig. 9.15, alongside size-fractionated photosynthetic rates.

\subsubsection{Derivation from rates of production and growth efficiencies}

Several studies (Robinson and Williams, 1999; Robinson et al. 1999, 2002a,b) have apportioned community respiration to that attributable to planktonic trophic groups using measured rates of bacterial production, microzooplankton herbivory, and / or bacterivory and algal photosynthesis together with an estimate of the respective growth efficiencies.

Bacterial respiration (BR) can be derived from measured bacterial production (BP) if the bacterial growth efficiency (BGE) can be estimated (i.e. $\mathrm{BR}=\mathrm{BP}(1-\mathrm{BGE}) / \mathrm{BGE})$. If not directly measured, bacterial growth efficiency is either taken from the range of published values, for example, $5-40 \%$, or derived from the equation $\left(\mathrm{BR}=3.7 \times \mathrm{BP}^{0.41}\right)$ reported by del Giorgio and Cole (1998) or the temperature relationship $\left(\mathrm{BGE}=0.374-0.0104 \times \mathrm{t}^{\circ} \mathrm{C}\right)$ of Rivkin and Legendre (2001). Bacterial growth efficiencies estimated by these two latter equations were found to differ by almost ninefold during a study of a coccolithophore bloom in the North Sea in June 1999 (Robinson et al. 2002b, also Table 9.2). Microzooplankton respiration ( $\mu \mathrm{ZR})$ can be derived 
from an estimate of herbivory, assuming a constant growth efficiency of $25 \%$ (Straile 1997) and an egestion + excretion rate of $20 \%$ (Robinson et al. $2002 b$ ). Algal respiration (AR) can be derived from the $R_{\max }: P_{\max }$ relationship of Langdon (1993) for the dominant autotroph present, that is, $0.16 \pm 0.04$ for Prymnesiophyceae and $0.35 \pm 0.17$ for Dinophyceae, where $P_{\max }$ is estimated from ${ }^{14} \mathrm{C}$ primary production or dissolved oxygen gross production measurements.

Given that one can estimate the rates for these various groups, overall community respiration should be equivalent to their sum (BR $+\mu \mathrm{ZR}+\mathrm{AR})$. In the studies where this type of accounting exercise has been attempted (Robinson and Williams 1999; Robinson et al. 1999, 2002a,b), the sum of the estimates of respiration attributable to the component plankton groups lie within $50 \%$ of the measured whole community respiration. This is probably as good as can be expected bearing in mind the levels of uncertainty on accepted measures of phyto, microzoo, and bacterioplankton activity, not to mention the four to tenfold range in measured and estimated growth efficiencies.

\subsubsection{Estimates from ${ }^{14} \mathrm{C}$ determination of net primary production}

Since net primary production (NPP) is equivalent to gross production (GP) minus algal respiration $(\mathrm{NPP}[\mathrm{C}]=\mathrm{GP}[\mathrm{C}]-\mathrm{AR}[\mathrm{C}])$, if one can assume that the ${ }^{14} \mathrm{C}$ technique measures net primary production, that gross production may be derived from oxygen flux $\left(\mathrm{GP}\left[\mathrm{O}_{2}\right]\right)$ and that it can be reliably converted to carbon flux GP[C] via a photosynthetic quotient (PQ), then algal respiration can be determined from the difference between $\mathrm{GP}\left[\mathrm{O}_{2}\right] / \mathrm{PQ}$ and ${ }^{14} \mathrm{C}$ uptake. Heterotrophic respiration (HR[C]) could then be determined from the difference between measured total community respiration in carbon units (R[C]) and this estimated algal respiration (AR[C]). The approach has not gained much popularity due to the uncertainty over whether or not, and when, the ${ }^{14} \mathrm{C}$ measures gross or net production, as well as the lesser problem of ascribing a value for the photosynthetic quotient however see Marra and Barber (2004).

\subsubsection{Inverse analysis}

As described in Section 9.2.5 above, several authors have used equations and models of carbon flow through the microbial food web to estimate the respiration attributable to a particular plankton group, for example, bacteria or size class, for example, $<5$ m (Fasham et al. 1999; Ducklow et al. 2000; Anderson and Ducklow 2001). Fasham et al. 1999 used a size structured ecosystem model forced with data collected during a 20 day spring bloom study in the NE Atlantic to conclude that $62 \%$ of the community respiration came from organisms $<5 \mu \mathrm{m}$ in size. The data extracted from this model are given in Table 9.2, along with that from a model of the food web of an oligotrophic oceanic region derived by Nagata (2000).

\subsubsection{Summary}

In Fig. 9.16, we have attempted to collate the results from these various approaches to the determination of the size distribution of respiration. Considering the scope for variation and error, the general pattern is remarkably consistent. All the approaches attribute a major proportion (70\% or more) of respiration to the smaller-size classes: $42 \pm 10 \%$ to organisms less than $1 \mu \mathrm{m}$ (the size class where bacterial biomass usually dominates), $32 \pm 20 \%$ to the size class $1-10 \mu \mathrm{m}$ (bacteria, protozoans, and phytoplankton). Much smaller proportions are found for the two larger-size classes: $6 \pm 5 \%$ to the class $10-100 \mu \mathrm{m}$ (the larger phytoplankton and protozoan ciliates) and the largest-size class (100-1000 $\mu \mathrm{m}-$ the larval and adult mesozooplankton) accounting for $10 \pm 8.5 \%$. Of course one should not expect a fixed pattern, as the composition of the plankton varies in space and with time.

\subsection{Synthesis and conclusions}

Respiration is one of the two determinants of the balance of organic material in the euphotic zone and the potential to export organic material to the deep ocean. As such it is a major influence on the scale of the biological pump-which sequesters carbon dioxide from the atmosphere. 


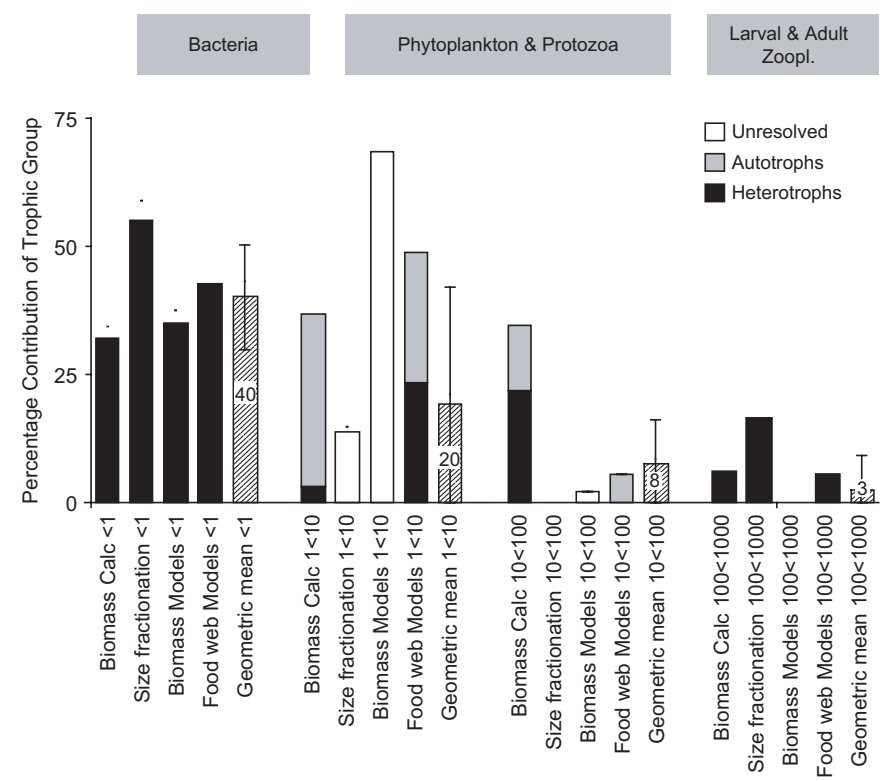

Figure 9.16 Summary of size distribution observations. The various analyses are grouped into categories <1 $\mu \mathrm{m}, 1-10 \mu \mathrm{m}, 10-100 \mu \mathrm{m}$, and 100-1 $000 \mu \mathrm{m}$. Where a distinction was made in the analyses between autotrophs and heterotrophs, this distinction has been retained, otherwise they are grouped as "unresolved".

\subsubsection{Estimation of global rates of respiration from direct field observations}

The "light/dark" bottle incubation technique is the primary method for measuring respiration. It is not without its errors and limitations, however it is without doubt in our minds as good, if not better, than other methods of measuring plankton metabolism. Acquiring appropriate sized datasets is massively costly in ship and human time. Nonetheless, since the late 1960s we have had reasonably good maps of oceanic photosynthesis based on in vitro observations. In the case of photosynthesis the problem is greatly simplified in that one can use measurements of light, chlorophyll and photosyntheticirradiance relationships to fill in the gaps. Satellite derived ocean color has rendered this as a powerful approach. No analogous approach is available for respiration. The present database of respiration is woefully inadequate-a mere 693 surface measurements covering an area of $320 \times 10^{6} \mathrm{~km}^{2}$. The ideal minimum would be seasonal descriptions of depth-integrated respiration for the 55 biogeochemical zones described by Longhurst (1998). Figure 9.2 makes it clear that we are a long way away from achieving this aim; a crude separation by $10^{\circ}$ of latitude still leaves a number of the latitude bands with no or very little data. This is frustrating as it leaves us uncertain whether or not the trends of respiration and net community production we see with latitude in Fig 9.13 are real or simply reflect inadequate sampling.

The respiration data are biased with respect to time, place, community structure, and depth, and so cannot provide a definitive global estimate of plankton respiration. However, they can be used to derive a maximum and minimum figure for global ocean photic zone respiration, which can then be compared with estimates derived from massbalance equations. Summing the latitudinal totals of depth-integrated respiration given in Fig. 9.13(b) gives a global (oceanic + coastal) respiration rate of $17.2 \mathrm{PmolO}_{2} \mathrm{a}^{-1}\left(186 \mathrm{GtCa}^{-1}\right.$, using a respiratory quotient of 0.89 , see Chapter 14 ). The mean depth-integrated respiration rate in oceanic waters of $116 \pm 8.5 \mathrm{mmol} \mathrm{O}_{2} \mathrm{~m}^{-2} \mathrm{~d}^{-1}$ equates to a global oceanic respiration rate of $13.5 \pm 1 \mathrm{PmolO}_{2} \mathrm{a}^{-1}$ $\left(146 \pm 12 \mathrm{GtCa}^{-1}\right)$. These are undoubtedly maximum values given the bias in sampling toward times and places of high productivity. The lowest values recorded in the database occur in the 
Southern Ocean (e.g. Bender et al. 2000) and during the autumn and winter (e.g. Serret et al. 1999) and give a lower limit to the estimate of oceanic respiration $\left(35 \mathrm{mmol} \mathrm{O}_{2} \mathrm{~m}^{-2} \mathrm{~d}^{-1} ; 4.1 \mathrm{Pmol} \mathrm{O}_{2} \mathrm{a}^{-1}\right.$; $\left.44 \mathrm{Gt} \mathrm{Ca}^{-1}\right)$. It is worth noting that the lowest estimate which could be derived from the dark oxygen incubation technique is $\sim 10 \mathrm{mmol} \mathrm{O}_{2} \mathrm{~m}^{-2} \mathrm{~d}^{-1}$ or 1.2 $\mathrm{PmolO}_{2} \mathrm{a}^{-1}\left(13 \mathrm{Gt} \mathrm{Ca}^{-1}\right)$ (based on a rate of $0.2 \mathrm{mmolO}_{2} \mathrm{~m}^{-3} \mathrm{~d}^{-1}$ and a $50 \mathrm{~m}$ euphotic zone) and so this lower dataset value is not simply a consequence of the limit of detection of the method. The 13-month study at HOTS provides a crucial seasonally integrated estimate of respiration in an area representative of the open-ocean gyres. The HOTS estimate $\left(31 \mathrm{~mol} \mathrm{O}_{2} \mathrm{~m}^{-2} \mathrm{a}^{-1}\right)$ would extrapolate to a global ocean estimate of $9.9 \mathrm{Pmol} \mathrm{O}_{2} \mathrm{a}^{-1}$ $\left(119 \mathrm{GtCa}^{-1}\right)$. Open-ocean primary production estimates, derived from ${ }^{14} \mathrm{C}$ measurements lie in the range $2.3-4.3 \mathrm{PmolCa}^{-1}\left(28-52 \mathrm{GtCa}^{-1}\right.$, del Giorgio and Duarte 2002). Comparisons between ${ }^{14} \mathrm{C}$ and gross production derived from dissolved oxygen flux suggest that ${ }^{14} \mathrm{C}$ underestimates gross production by 35-65\% (Bender et al. 1999; Robinson and Williams 1999; Laws et al. 2000; Rees et al. 2002). Correcting the open-ocean production estimates by a mean of $50 \%$ gives a range of $5-9 \mathrm{Pmol} \mathrm{Ca}^{-1}$ (see also Chapter 14). Comparison with the range in respiration estimates (4-17 $\mathrm{Pmol} \mathrm{Ca}^{-1}$ ) could be seen as a major imbalance in the functioning of the oceans but more likely arises from a lack of our understanding in the seasonal and regional variations in photosynthesis and respiration.

\subsubsection{Derivation of global rates from correlation analysis}

Recognizing the limitations in the current database of respiration, several authors have attempted to derive simple relationships between respiration and indicators of plankton biomass (Robinson et al. $2002 a, b$ ) or photosynthesis (del Giorgio et al. 1997; Duarte and Agusti 1998; Serret et al. 2001). The analysis we have made in the present chapter (Section 8.3.2) on an enlarged database is not encouraging in this respect. Only $20-30 \%$ of the variance in respiration can be accounted for by the variation in routinely measured indicators of plankton biomass. The low correlation between respiration and photosynthesis precludes the use of this simple property relationship to make useful global predictions of respiration-consistent with the arguments of Williams and Bowers (1999) and Serret et al. (2001, 2002). As the major source of carbon for oceanic respiration comes from oceanic photosynthesis (see Box 9.2) there has to be some form of relationship, although clearly it is not a simple one.

\subsubsection{Derivation of rates from ocean organic mass-balance calculations}

Simple mass-balance calculations enable us to derive a fairly precise estimate of the difference between production and consumption and so in principle provide a constraint to the global estimates of respiration derived from direct measurements. The strength of the mass-balance calculation is that the assumptions are clear and the implication of differing assumptions easy to explore. Their limitation is that they cannot give an independent estimate of both photosynthesis and respiration. The calculation also implicitly assumes steady state over the medium term (10-100 years). This assumption appears to be justifiable as the size of the principal organic reservoir in the upper water column (about 5-8 $\mathrm{mol} \mathrm{DOC}^{-2}$ ) is about a third or less than that of the annual biological turnover of carbon. Thus if there were persistent imbalances in the upper water column carbon cycle, major changes in the carbon reservoirs would result. We have reasonably reliable observations of DOC concentrations that span 45 years and can be fairly certain that major changes in the DOC pool have not occurred. As estimates of the external organic inputs into the ocean (predominantly river-borne material) exceed those of the outputs (predominantly sedimentation), the ocean as a whole must be net heterotrophic, albeit only very slightly $(0.4 \%$, see Box 9.2). This was essentially the argument of Smith and Mackenzie (1987). The difference between production and consumption is small, in relation to the individual processes themselves. Any estimate we obtain for respiration from mass-balance calculations is primarily dependent upon the value we take for oceanic primary production, so in a way we cycle back to the problem 


\section{Box 9.2 Mass-balance calculations for respiration in the whole oceanic water column}

The basic mass-balance equation assumes that as there is no accumulation of organic material, the sum of all the inputs must equal that of all the outputs:

$$
\text { that is, } P+\sum l-\left(R+\sum O\right)=0 \text {, }
$$

\section{where:}

$P$ is the annual rate of photosynthesis;

$R$ is the annual rate of respiration;

$\sum I$ is the sum of the external inputs;

$\sum O$ is the sum of the external outputs from the oceanic water column.

The calculation considers annual sums of all the individual sources and sinks, the units are $\mathrm{Tmol} \mathrm{C} \mathrm{a}^{-1}$.
The individual inputs (see Williams 2000) are:

$I_{R}=$ river input of organic material $=34 \mathrm{Tmol} \mathrm{Ca}^{-1}$;

$I_{A}=$ atmospheric deposition of organic material $=$ $2 \mathrm{Tmol}_{\mathrm{Ca}} \mathrm{a}^{-1}$

The individual outputs (see Williams 2000) are:

$O_{S}=$ net sedimentation $=14 \mathrm{Tmol} \mathrm{Ca}^{-1}$;

$\mathrm{O}_{\mathrm{A}}=$ input of organic material into the atmosphere $=$ $2 \mathrm{Tmol} \mathrm{Ca}^{-1}$

Then, $P+36-(R+16)=0$, thus $R=P+20$.

If we take $5500 \mathrm{Tmol} \mathrm{Ca}^{-1}$ as an estimate of whole ocean gross production (see Box 9.3), then $R=5500+20=$ $5520 \mathrm{Tmol} \mathrm{Ca}^{-1}$ and $P / R=0.996$.

Trophic balance $=0.4 \%$ heterotrophic. of the uncertainties inherent in this latter estimate. However the one thing we can be certain of from the mass-balance calculation is that there cannot be the massive difference between oceanic production and respiration we derive from analysis of field observations.

Whereas the mass-balance approach is a useful technique on the large scale, it quickly runs into severe limitations when it is attempted for subdivisions of the ocean. In Box 9.3, the calculation is repeated with the simple division of the oceans into the coastal-and the open-ocean zones. The export of organic carbon from the coastal to the open ocean has been part of a major international program (LOICZ-Land-Ocean Interactions in the Costal Zone). The overall spread of values for the total export from the coastal to the open ocean is large but we seem to be approaching some consensus in the estimates. Liu et al. (2000b) reported a range from 17 to $390 \mathrm{TmolCa}^{-1}$. They regard $70 \mathrm{Tmol} \mathrm{Ca}^{-1}$ to be a representative value. Ducklow and McCallister (in press) adopt a higher figure of $200 \mathrm{TmolCa}^{-1}$. These two estimates (70 and $200 \mathrm{Tmol} \mathrm{Ca}^{-1}$ ) probably bracket the likely range and have been used in Box 9.3 to calculate maximum and minimum scenarios. In both situations the open-ocean water column is calculated to be net heterotrophic, weakly so $(1.7 \%)$ in the low export case, more significantly so $(5 \%)$ in the high export case. The higher figure for carbon export to the open ocean calls for a strongly $(13 \%)$ autotrophic coastal ocean, the lower export figure, a weakly (3\%) autotrophic one.

As the focus of this chapter is the epipelagic zone, we have made mass-balance calculations for this zone. It is regarded (Liu et al. 2000a; Ducklow and McCallister in press) that the export of organic material from the coastal ocean occurs down the continental slope and thus enters the mesopelagic, rather than the epipelagic zone. This leaves the budget for the epipelagic dominated by a single import/export term: the transfer of material to the mesopelagic zone. Recent estimates for the export to the mesopelagic are $667 \mathrm{TmolC} \mathrm{a}^{-1}$ (Liu et al. 2000b), $782 \mathrm{TmolC}^{-1}$ (Ducklow and McCallister, in press), $1700 \mathrm{TmolCa}^{-1}$ (Arístegui, Chapter 10) and $2292 \mathrm{Tmol} \mathrm{Ca}^{-1}$ (del Giorgio and Duarte 2002). In Box 9.4 we have calculated a budget for the epipelagic zone using the two extremes, as well as an intermediate figure of $1000 \mathrm{TmolCa}^{-1}$. The broad pattern is the same-it requires the epipelagic ocean to be distinctly (16-57\%) net autotrophic. The difference between photosynthesis and respiration in the epipelagic (euphotic) zone is set by the 


\section{Box 9.3 Mass-balance calculations for respiration in the coastal and open ocean water columns}

Separate calculations are made for coastal (area $=0.36 \times 10^{14} \mathrm{~m}^{2}$ ) and oceanic (area $=3.2 \times 10^{14} \mathrm{~m}^{2}$ ) zones. The sedimentation rates for the coastal and open ocean zones are taken as 12 and $2 \mathrm{Tmol} \mathrm{Ca}^{-1}$, respectively (see Box 9.2). The output to atmosphere $\left(O_{A}=2 \mathrm{Tmol} \mathrm{Ca}^{-1}\right.$, see Box 9.2) is divided pro rata by area between the coastal and open ocean giving, respectively, 0.2 and $1.8 \mathrm{Tmol} \mathrm{Ca}^{-1}$. The input from the atmosphere $\left(I_{A}=2 \mathrm{Tmol} \mathrm{Ca}^{-1}\right.$, see Box 9.2$)$ has been apportioned assuming twice the fallout rate in the coastal zone giving 0.36 and $1.64 \mathrm{Tmol} \mathrm{Ca}^{-1}$, respectively for the coastal and open ocean zones. Neither of these last two estimates is critical in the calculation. Estimates for the productivity of the coastal ocean vary three to fourfold: Liu et al. (2000 b) gives a range of $340-750 \mathrm{Tmol} \mathrm{Ca}^{-1}$. We adopt Ducklow and McCallister's (in press) recent estimate of $1200 \mathrm{Tmol} \mathrm{Ca}^{-1}$ for net primary production and maintain a ratio of coastal to oceanic production similar to that of Ducklow and McCallister (in press). As we need to base the calculation on gross production, we scale up net primary production by $25 \%$ to give gross production so obtaining a figure of $1500 \mathrm{Tmol} \mathrm{Ca}^{-1}$ for the coastal ocean and $4000 \mathrm{Tmol} \mathrm{Ca}^{-1}$ for the open ocean. The final terms $\left(O_{0}\right.$ and $\left./ \mathrm{C}\right)$, the output from the coastal production to the open ocean and the import of organic matter produced in coastal waters, must be numerically equal. Two situations have been calculated, a low value $\left(70 \mathrm{Tmol} \mathrm{Ca}^{-1}\right)$ for $O_{0}$ is taken from Liu et al. $(2000 \mathrm{~b})$ and a high value (200 Tmol C $\mathrm{a}^{-1}$ ) from Ducklow and McCallister (in press). The calculations (see Box 9.2 for notation) are as follows:

Coastal ocean: mass-balance equation

$$
P+I_{A}+I_{R}-\left(R+O_{S}+O_{A}+O_{R}+O_{0}\right)=0 \quad P+I_{A}+I_{R}+I_{C}-\left(R+O_{S}+O_{A}\right)=0
$$

Authors vary over whether to separate organic material of planktonic and river origin in their estimates of export from the coastal zone, it is a detail that is unnecessary in the present account and so these export/import terms have been embedded as single values $\left(O_{0}\right.$ and $\left.I_{C}\right)$. The above equations then simplify to:

Coastal ocean: mass-balance equation

$$
P+I_{A}+I_{R}-\left(R+O_{S}+O_{A}+O_{0}\right)=0
$$

Coastal ocean: high export calculation

$$
P+0.36+34-(R+12+0.2+200)=0
$$

Thus, $R=P-178 \mathrm{Tmol} \mathrm{Ca}^{-1}$

Assume, $P=1500 \mathrm{Tmol} \mathrm{Ca}^{-1}$.

Then $R=1322 \mathrm{Tmol} \mathrm{Ca}^{-1}$, and $P / R=1.13$.

Coastal ocean would be $12 \%$ autotrophic.

Coastal ocean: low export calculation

$$
P+0.36+34-(R+12+0.2+70)=0
$$

Thus, $R=P-48 \mathrm{Tmol} \mathrm{Ca}^{-1}$.

Then $R=1452 \mathrm{Tmol} \mathrm{Ca}^{-1}$ and $P / R=1.03$.

Coastal ocean would be $3 \%$ autotrophic.
Open ocean: mass-balance equation

$$
P+I_{\mathrm{A}}+I_{C}-\left(R+O_{S}+O_{A}\right)=0
$$

Open ocean: high export calculation

$$
\begin{aligned}
& P+1.6+200-(R+2+1.8)=0 \\
& \text { Thus, } R=P+198 \mathrm{Tmol} \mathrm{Ca}^{-1} \text {. } \\
& \text { Assume, } P=4000 \mathrm{Tmol} \mathrm{Ca}^{-1} \text {. } \\
& \text { Then } R=4198 \mathrm{Tmol} \mathrm{Ca}^{-1} \text { and } P / R=0.95 \text {. } \\
& \text { Open ocean would be } 5 \% \text { heterotrophic. } \\
& \text { Open ocean: low export calculation } \\
& P+1.6+70-(R+2+1.8)=0 \\
& \text { Thus, } R=P+68 \mathrm{Tmol}^{\mathrm{C}} \mathrm{Ca}-1 \\
& \text { Then, } R=4068 \mathrm{Tmol}^{-1} \mathrm{Ca}^{-1} \text {, and } P / R=0.98 \text {. } \\
& \text { Open ocean would be } 1.7 \% \text { heterotrophic. }
\end{aligned}
$$




\section{Box 9.4 Mass-balance calculation for the open ocean epipelagic zone}

The prevailing view is that the exported planktonic production from the coastal regions enters the mesopelagic, rather than the epipelagic zone of the open ocean (see Liu et al., 2000a; Arístegui et al., Chapter 10). We make calculations for the epipelagic $(0-150 \mathrm{~m})$ zone of the ocean, assuming that coastal production is exported to the mesopelagic zones. We may expect that the material of river origin passes into both zones, however as will be seen below whatever assumption we make of its fate is of little consequence in the overall calculation.

\section{Mass-balance equation,}

$$
P+I_{A}+I_{R}+I_{C}-\left(R+O_{M}+O_{A}\right)=0,
$$

where $O_{M}$ is the export from the epipelagic into the mesopelagic zone.

to:

$$
\text { As } O_{M}>>\left(O_{A}+I_{A}+I_{R}+I_{C}\right) \text {, the equation simplifies }
$$

$$
P-\left(R+O_{M}\right)=0 .
$$

Recent estimates for the export to the mesopelagic $\left(O_{M}\right)$ are $667 \mathrm{Tmol} \mathrm{Ca}^{-1}$ (Liu et al. 2000a), $782 \mathrm{Tmol} \mathrm{Ca}^{-1}$ (Ducklow and McCallister in press), $1700 \mathrm{Tmol} \mathrm{Ca}^{-1}$ (Arístegui et al., Chapter 10) and $2292 \mathrm{Tmol} \mathrm{Ca}^{-1}$ (del Giorgio and Duarte 2002). Here we make the calculation for the extremes of the estimate of $\mathrm{O}_{\mathrm{M}}\left(667\right.$ and $\left.2292 \mathrm{Tmol} \mathrm{Ca}^{-1}\right)$, and what would seem be a median value of $1000 \mathrm{Tmol} \mathrm{Ca}^{-1}$.

Epipelagic ocean: low export calculation

$R=P-667 \mathrm{Tmol} \mathrm{Ca}^{-1}$.

Then $R=3333 \mathrm{Tmol} \mathrm{Ca}^{-1}$,

and $P / R=1.2$.

Epipelagic ocean: would need to be $16 \%$ autotrophic.

Epipelagic ocean: high export calculation

$R=P-2292 \mathrm{Tmol} \mathrm{Ca}^{-1}$

Then $R=1708 \mathrm{Tmol} \mathrm{Ca}^{-1}$,

and $P / R=2.3$.

Epipelagic ocean would need to be $57 \%$ autotrophic.

Epipelagic ocean: intermediate export calculation

$R=P-1000 \mathrm{Tmol} \mathrm{Ca}^{-1}$.

Then $R=3000 \mathrm{Tmol} \mathrm{Ca}^{-1}$,

and $P / R=1.33$.

Epipelagic ocean would need to be $25 \%$ autotrophic. export term, which is reasonably well constrained; if anything it may be an underestimate thus requiring even higher levels of net autotrophy. Whereas the difference between photosynthesis and respiration is determined by a single term, the absolute values are dependent upon the value taken for oceanic photosynthesis. del Giorgio and Duarte (2002) in their review adopted a twofold spread of values-their upper figure for the ocean as a whole (6400 $\mathrm{TmolC}^{-1}$ ) is somewhat higher than the one we have used and it would reduce the calculated relative net autotrophy to a range of $14-49 \%$.

Significantly, the range of epipelagic zone oceanic respiration rates derived from mass-balance considerations (1.7-3 $\mathrm{PmolC}^{-1}$ ) lie below even the lowest estimate of oceanic respiration derived from direct measurements, and are two to eightfold lower than the mid- and highest estimates derived from direct measurements. This does not derive from an error in the mass-balance calculation, but for the need to supply a figure for the rate of photosynthesis-essentially we return to the problem brought to light in the preceding paragraph. The prediction from mass-balance equations that the epipelagic zone is $25 \%$ or so autotrophic is at odds with the direct measurements that imply a balanced or slightly heterotrophic situation. This discrepancy will in part result from the different time and space scales considered by the two approaches. However, they also point to the weaknesses in our understanding of the global balance between organic carbon production and respiration. Mass-balance equations and direct observations indicate (del Giorgio and Duarte 2002; Williams et al. in press) that we may be underestimating the rate of organic matter production, by a factor of two or more. In the final chapter (Chapter 14) del Giorgio and Williams discuss this in more detail and achieve some resolution of the problem. Combined with the sampling bias of oceanic respiration measurements, our appreciation 
of regional and global photosynthesis to respiration balances is rudimentary. If we are to predict the oceans's response to global change, then current and future national and international oceanographic programs will need to incorporate the determination of oceanic respiration and to address the question of whether the ocean biota act as a net source or sink of carbon as a priority research objective.

\section{Acknowledgments}

Many thanks to the following for making published and unpublished data available: Javier Arístegui, Natalia Gonzalez, Dominique Lefèvre, Paul Morris, and Nelson Sherry, and to Alison Fairclough at the British Oceanographic Data Centre (BODC) for her meticulous help in accessing the UK BOFS, PRIME, and Arabesque data. CR was funded on a NERC Advanced Research Fellowship (GT5/96/8/MS) and the Plymouth Marine Laboratory Core Strategic Research Programme. Satellite data in Fig. 9.2 were processed by Gareth Mottram and Peter Miller at the Plymouth Marine Laboratory Remote Sensing Group (www.npm.ac.uk/rsdas/). SeaWiFS data courtesy of the NASA SeaWiFS project and Orbital Sciences Corporation.

\section{References}

Abell, J., Emerson, S., and Renaud, P. 2000. Distributions of TOP, TON and TOC in the North Pacific subtropical gyre: implications for nutrient supply in the surface ocean and remineralization in the upper thermocline. J. Mar. Res., 58: 203-222

Anderson, T. R. and Ducklow, H. W. 2001. Microbial loop carbon cycling in ocean environments studied using a simple steady-state model. Aquat. Microb. Ecol., 26: 37-49.

Arístegui, J. and Harrison, W. G. 2002. Decoupling of primary production and community respiration in the ocean: implications for regional carbon studies. Mar. Ecol. Prog. Ser., 29: 199-209.

Arístegui, J. and Montero, M. F. 1995. The relationship between community respiration and ETS activity in the ocean. J. Plankton Res., 17: 1563-1571.

Arístegui, J., Montero, M. F., Ballesteros, S., Basterretxea, G., and van Lenning, K. 1996. Planktonic primary production and microbial respiration measured by ${ }^{14} \mathrm{C}$ assimilation and dissolved oxygen changes in coastal waters of the Antarctic Peninsula during the austral summer: implications for carbon flux studies. Mar. Ecol. Prog. Ser., 132: 191-201.

Arístegui, J., Denis, M., Almunia, J., and Montero, M. F. 2002. Water-column remineralization in the Indian sector of the Southern Ocean during early Spring. Deep-Sea Res. II, 49: 1707-1720.

Barber, R. T. and Hilting, A. K. 2002. History of the study of Plankton Productivity. In P. J. le B. Williams, D. N. Thomas, and C. S. Reynolds (eds) Phytoplankton Productivity: Carbon Assimilation in Marine and Freshwater Ecosystems. Blackwell Science Ltd, Oxford, UK, p. 386.

Bender, M., Grande, K., Johnson, K., Marra, J., Williams, P. J. le B., Sieburth, J., Pilson, M., Langdon, C., Hitchcock, G., Orchardo, J., Hunt, C., Donaghay, P., and Heinemann, K. 1987. A comparison of four methods for determining planktonic community production. Limnol. Oceanogr., 32: 1085-1097.

Bender, M., Orchardo, J., Dickson, M-L., Barber, R., and Lindley, S. 1999. In vitro $\mathrm{O}_{2}$ fluxes compared with ${ }^{14} \mathrm{C}$ production and other rate terms during the JGOFS Equatorial Pacific experiment. Deep-Sea Res. I, 46: 637-654.

Bender, M. L. 2000. Tracer from the sky. Science, 288: 19771978.

Bender, M. L., Dickson, M-L., and Orchardo, J. 2000. Net and gross production in the Ross Sea as determined by incubation experiments and dissolved $\mathrm{O}_{2}$ studies. DeepSea Res. II, 47: 3141-3158.

Blanco, J. M., Quinones, R. A., Guerrero, F., and Rodriguez, J. 1998. The use of biomass spectra and allometric relations to estimate respiration of plankton communities. J. Plankton Res., 20: 887-900.

Blight, S. P., Bentley, T. L., Lefèvre, D., Robinson, C., Rodrigues, R., Rowlands, J., and Williams P. J. le B. 1995. The phasing of autotrophic and heterotrophic plankton metabolism in a temperate coastal ecosystem. Mar. Ecol. Prog. Ser., 128: 61-74.

Biddanda, B., Opsahl, S., and Benner, R. 1994. Plankton respiration and carbon flux through bacterioplankton on the Louisiana shelf. Limnol. Oceanogr., 39: 1259-1275.

Boyd, P., Robinson, C., Savidge, G., and Williams, P. J. le B. 1995. Water column and sea ice primary production during austral spring in the Bellingshausen Sea. Deep-Sea Res. II, 42: 1177-1200.

Carlson, C. A., Bates, N. R. T., Ducklow, H. W., and Hansell, D. F. A. 1999. Estimation of bacterial respiration and growth efficiency in the Ross Sea, Antarctica. Aquat. Microb. Ecol., 19: 229-244. 
Chipman, D. W., Marra, J., and Takahashi, T. 1993. Primary production at $47^{\circ} \mathrm{N} 20^{\circ} \mathrm{W}$ in the North Atlantic Ocean: a comparison between the ${ }^{14} \mathrm{C}$ incubation method and the mixed layer carbon budget. Deep-Sea Res. II, 40: 151-169. Christensen, J. P., Owens, T. G., Devol, A. H., and Packard, T. T. 1980. Respiration and physiological state in marine bacteria. Mar. Biol., 55: 267-276.

Cota, G. F., Pomeroy, L. R., Harrison, W. G., Jones, E. P., Peters, F., Sheldon, Jr., W. M., and Weingartner, T. R. 1996. Nutrients, primary production and microbial heterotrophy in the southeastern Chukchi Sea: Arctic summer nutrient depletion and heterotrophy Mar. Ecol. Prog. Ser., 135: 247-258.

del Giorgio, P. A. 1992. The relationship between ETS (electron transport system) activity and oxygen consumption in lake plankton-a cross system calibration. J. Plankton Res., 14: 1723-1741.

del Giorgio, P. A. and Cole, J. J. 1998. Bacterioplankton growth efficiency in natural aquatic systems. Annu. Rev. Ecol. Syst., 29: 503-541.

del Giorgio, P. A. and Duarte, C. M. 2002. Respiration in the open ocean. Nature, 420: 379-384.

del Giorgio, P. A., Cole, J. J., and Cimbleris A. 1997. Respiration rates in bacteria exceed plankton production in unproductive aquatic systems. Nature, 385: 148-151.

Daneri, G. 1992. Comparison between in vitro and in situ estimates of primary production within two tracked water bodies. Arch. Hydrobiol. Beih., 37: 101-109.

Daneri, G., Dellarossa, V., Quinones, R., Jacob, B., Montero, P. and Ulloa, O. 2000. Primary production and community respiration in the Humboldt current system off Chile and associated oceanic areas. Mar. Ecol. Prog. Ser., 197: 41-49.

Dickson, M.-L. and Orchardo, J. 2001. Oxygen production and respiration in the Antarctic Polar Front region during the austral spring and summer. Deep-Sea Res. II, 48: 4101-4126.

Dickson, M.-L., Orchard, J., Barber, R. T., Marra, J., McCarthy, J. J., and Sambrotto, R. N. 2001. Production and respiration rates in the Arabian Sea during the 1995 Northeast and Southwest Monsoons. Deep-Sea Res. II, 48: 1199-1230.

Duarte, C. M. and Agusti S. 1998. The $\mathrm{CO}_{2}$ balance of unproductive aquatic ecosystems. Science. 281: 234-236.

Duarte, C. M., Agusti, S., Arístegui, J., Gonzalez, N., and Anadon, R. 2001. Evidence for a heterotrophic subtropical northeast Atlantic. Limnol. Oceanogr., 46: 425-428.

Ducklow, H. W. and S. L. McCallister. In press. The biogeochemistry of carbon dioxide in the coastal oceans.
Chapter 10 In The Sea. Volume 13 The Global Coastal Ocean: Multiscale Interdisciplinary Processes. A. R. Robinson, K. Brink, H. W. Ducklow, R. Jahnke and B. J. Rothschild. eds. Harvard University Press. Cambridge, MA. pp

Ducklow, H. W., Dickson, M-L., Kirchman, D. L., Steward, G., Orchardo, J., Marra, J., and Azam, F. 2000. Constraining bacterial production, conversion efficiency and respiration in the Ross Sea, Antarctica, January-February, 1997. Deep-Sea Res. II, 47: 3227-3247.

Eissler, Y. and Quinones, R. A. 1999. Microplanktonic respiration off northern Chile during El Nino 1997-1998. J. Plankton Res. 21: 2263-2283.

Emerson, S., Quay, P., Karl, D., Winn, C., Tupas, L., and Landry, M. 1997. Experimental determination of the organic carbon flux from open ocean surface waters. Nature, 389: 951-954.

Emerson, S., Stump, C., Johnson, B., and Karl, D. M. 2002. In situ determination of oxygen and nitrogen dynamics in the upper ocean. Deep-Sea Res. I, 49: 941-952.

Fasham, M. J. R., Boyd, P. W., and Savidge, G. 1999. Modeling the relative contributions of autotrophs and heterotrophs to carbon flow at a Lagrangian JGOFS station in the Northeast Atlantic: the importance of DOC. Limnol. Oceanogr., 44: 80-94.

Gonzalez, N., Anadon, R., Mourino, B., Fernandez, E., Sinha, B., Escanez, J., and de Armas, D. 2001. The metabolic balance of the planktonic community in the north Atlantic subtropical gyre: the role of mesoscale instabilities. Limnol. Oceanogr., 46: 946-952.

Gonzalez, N., Anadon, R., and Maranon, E. 2002 Large-scale variability of planktonic net community metabolism in the Atlantic ocean: importance of temporal changes in oligotrophic subtropical waters. Mar. Ecol. Prog. Ser., 333: 21-30.

Grande, K. D., Marra, J., Langdon, C., Heinemann, K., and Bender, M. 1989a. Rates of respiration in the light measured in marine phytoplankton using an ${ }^{18} \mathrm{O}$ isotope labelling technique. J. Exp. Mar. Biol. Ecol., 129: 95-120.

Grande, K. D., Williams, P. J. le B., Marra, J., Purdie, D. A., Heinemann, K., Eppley, R. W., and Bender, M. L. 1989b. Primary production in the North Pacific gyre: a comparison of rates determined by the ${ }^{14} \mathrm{C}, \mathrm{O}_{2}$ concentration and ${ }^{18} \mathrm{O}$ methods. Deep-Sea Res. I, 36: 1621-1634.

Griffith, P. C., Douglas, D. J., and Wainwright, S. C. 1990. Metabolic activity of size-fractionated microbial plankton in estuarine, near shore, and continental shelf waters of Georgia. Limnol. Oceanogr., 59: 263-270.

Hanson, A. K., Tindale, N. W., and Abdel-Moatia, M. A. R. 2001. An Equatorial Pacific rain event: influence on the 
distribution of iron and hydrogen peroxide in surface waters. Mar. Chem., 75: 69-88.

Harrison, W. G. 1986. Respiration and its size-dependence in microplankton populations from surface waters of the Canadian Arctic. Polar Biol., 6: 145-152.

Harrison, W. G., Arístegui, J., Head, E. J. H., Li, W. K. W., Longhurst, A. R., and Sameoto, D. D. 2001. Basinscale variability in plankton biomass and community metabolism in the sub-tropical North Atlantic Ocean. Deep-Sea Res. II, 48: 2241-2269.

Herut, B., Shoham-Frider, E., Kress, N., Fiedler, U., and Angel, D. L. 1998. Hydrogen peroxide production rates in clean and polluted coastal marine waters of the Mediterranean, Red and Baltic Seas. Mar. Pollut. Bull. 36 994-1003.

Hitchcock, G. L., Vargo, G. A., and Dickson, M-L. 2000. Plankton community composition, production and respiration in relation to dissolved inorganic carbon on the West Florida shelf, April 1996. J. Geophys. Res., 105: 6579-6589.

Holligan, P M, Williams, P. J. le B., Purdie, D. A., and Harris, R. P. 1984. Photosynthesis, respiration and nitrogen supply of plankton populations in stratified, frontal and tidally mixed shelf waters Mar. Ecol. Prog. Ser., 17 201-203.

Hopkinson, C. S., Sherr, B., and Wiebe, W. J. 1989. Size fractionated metabolism of coastal microplankton. Mar. Ecol. Prog. Ser., 51: 155-166.

Jacquet, S., Partensky, F., Lennon, J. F., and Vaulot, D. 2001. Diel patterns of growth and division in marine picoplankton in culture J. Phycol., 37: 357-369.

Jahnke, R. A. and Craven, D. B. 1995. Quantifying the role of heterotrophic bacteria in the carbon cycle: a need for respiration rate measurements. Limnol. Oceanogr., 40: 436-441.

Jenkins, W. J. and Goldman, J. C. 1985. Seasonal oxygen cycling and primary production in the Sargasso Sea. J. Mar. Res., 43: 465-491.

Johnson, K. M., Davis, P. G., and Sieburth, J. MCN. 1983. Diel variation of $\mathrm{TCO}_{2}$ in the upper layer of oceanic waters reflects microbial composition, variation and possibly methane cycling. Mar. Biol., 77: 1-10.

Johnson, K. M., Sieburth, J. McN., Williams, P. J. le B., and Brandstrom, L. 1987. Coulometric total carbon dioxide analysis for marine studies: automation and calibration. Mar. Chem., 21: 117-133.

Karl, D. M., Morris P. J., Williams, P. J. le B., and Emerson, S. 2003. Metabolic balance of the open sea Nature, 426: 32.

Keeling, R. F. and Shertz, S. R. 1992. Seasonal and interannual variations in atmospheric oxygen and implications for the global carbon cycle Nature, 358 723-727.

Kenner, R. A. and Ahmed, S. I. 1975. Measurements of Electron transport activities in marine phytoplankton. Mar. Biol., 33: 119-127.

Kiddon, J., Bender, M. L., and Marra, J. 1995. Production and respiration in the 1989 North Atlantic Spring bloom-an analysis of irradiance dependent changes Deep-Sea Res. I, 42: 553-576.

Kruse, B. 1993. Measurement of plankton $\mathrm{O}_{2}$ respiration in gas-tight plastic bags. Mar. Ecol. Prog. Ser., 94: 155-163.

Langdon, C. 1993. The significance of respiration in production measurements based on oxygen. ICES Mar. Sci. Symp., 197: 69-78.

Laws, E. A., Landry, M. R., Barber, R. T., Campbell, L., Dickson, M.-L., and Marra, J. 2000. Carbon cycling in primary production incubations: inferences from grazing experiments and photosynthetic studies using ${ }^{14} \mathrm{C}$ and ${ }^{18} \mathrm{O}$ in the Arabian Sea. Deep-Sea Res. II, 47: 1339-1352.

Lefèvre, D., Minas, H. J., Minas, M., Robinson, C., Williams, P. J. le B., and Woodward, E. M. S. 1997. Review of gross community production, primary production, net community production and dark community respiration in the Gulf of Lions Deep-Sea Res. II, 44: 801-832.

Liu, K. K. Atkinson, L., Chen, C. T. A., Gao, S., Hall, J. Macdonald, R. W., McManus, L. T., and Quinones, R. $2000 a$. Exploring continental margin carbon fluxes on a global scale EOS, 81: 641-642.

Liu K.-K., Iseki, K., and Chao, S.-Y. 2000b. Continental margin carbon fluxes. In R. B. Hanson, H. W. Ducklow, and J. G. Field (eds) The Changing Ocean Carbon Cycle: A Midterm Synthesis of the Joint Global Ocean Flux Study IGBP Series 3. Cambridge University, Press, Cambridge, UK, pp. 187-239.

Longhurst, A. 1998. Ecological Geography of the Sea. Academic Press, San Diego, p. 398.

Luz, B. and Barkan, E. 2000. Assessment of oceanic productivity with the triple-isotope composition of dissolved oxygen. Science, 288: 2028-2031.

Marra, J. and Barber, R. T. 2004. Phytoplankton and heterotrophic respiration in the surface layer of the ocean. Geophys. Res. Lett. 31: L09314.

Marra, J. and Heinemann, K. 1984. A comparison between non contaminating and conventional incubation procedures in primary production measurements. Limnol. Oceanogr., 29: 389-392.

Moffett, J. W. and Zafiriou, O. C. 1993. The photochemical decomposition of hydrogen peroxide in surface waters of the eastern Caribbean and Orinoco River. J. Geophys. Res. Oceans, 98: 2307-2313. 
Moncoiffe, G., Alvarez-Salgado, X. A., Figueiras, F. G., and Savidge, G. 2000. Seasonal and short-time-scale dynamics of microplankton community production and respiration in an inshore upwelling system. Mar. Ecol. Prog. Ser., 196: 111-126.

Nagata, T. 2000. Production mechanisms of dissolved organic matter. In D. L. Kirchman (ed.) Microbial Ecology of the Oceans. John Wiley and Sons, Inc., New York.

Packard, T. T. 1971. The measurement of respiratory electron transport activity in marine phytoplankton. J. Mar. Res., 29: 235-244.

Packard, T. T. 1985. The measurement of respiratory electron transport activity in microplankton. In H. W. Jannasch and P. J. le B. Williams (eds) Advances in Aquatic Microbiology. Vol. 3 Academic Press, London, pp. 207-261.

Packard, T., Berdalet, E., Blasco, D., Roy, S. O., St-Amand, L., Lagace, B., Lee, K., and Gagne, J.-P. 1996. $\mathrm{CO}_{2}$ production predicted from isocitrate dehydrogenase activity and bisubstrate enzyme kinetics in the marine bacterium Pseudomonas nautica. Aquat. Microb. Ecol. 11: 11-19.

Pamatmat, M. M. 1997. Non-photosynthetic oxygen production and non-respiratory oxygen uptake in the dark: a theory of oxygen dynamics in plankton communities. Mar. Biol., 129: 735-746.

Platt, T. and Denman, K. 1978. The structure of pelagic marine ecosystems. Rapp. P.-V. Reun. Cons. Int. Explor. Mer., 173: 60-65.

Platt, T., Lewis, M., and Geider, R. 1984. Thermodynamics of the pelagic ecosystem: elementary closure conditions for biological production in the open ocean. In M. J. R. Fasham (ed.) Flows of Energy and Materials in Marine Ecosystems. Plenum Press, New York, pp. $49-84$.

Pomeroy, L. R., Sheldon, J. E., and Sheldon, W. M. 1994. Changes in bacterial numbers and leucine assimilation during estimations of microbial respiratory rates in seawater by the precision Winkler method. Appl. Environ. Microbiol., 60: 328-332.

Pomeroy, L. R., Sheldon, J. E., Sheldon Jr., W. M., and Peters, F. 1995. Limits to growth and respiration of bacterioplankton in the Gulf of Mexico. Mar. Ecol. Prog. Ser., 117: 259-268.

Rees, A. P., Joint, I., Woodward, E. M. S., and Donald, K. M. 2001. Carbon, nitrogen and phosphorus budgets within a mesoscale eddy: comparison of mass balance with in vitro determinations. Deep-Sea Res. II, 48: 859-872.

Rees, A. P., Woodward, E. M. S., Robinson, C., Cummings, D. G., Tarran, G. A., and Joint, I. 2002. Size fractionated nitrogen uptake and carbon fixation during a developing coccolithophore bloom in the North Sea during June 1999. Deep-Sea Res. II, 49: 2905-2927.

Rivkin, R. B. and Legendre, L. 2001. Biogenic carbon cycling in the upper ocean: effects of microbial respiration. Science, 291: 2398-2400.

Robinson, C. 2000. Plankton gross production and respiration in the shallow water hydrothermal systems of Milos, Aegean Sea. J. Plankton Res., 22: 887-906.

Robinson, C. and Williams, P. J. le B. 1991. Development and assessment of an analytical system for the accurate and continual measurement of total dissolved inorganic carbon Mar. Chem., 34: 157-175.

Robinson, C. and Williams, P. J. le B. 1993. Temperature and Antarctic plankton community respiration J. Plankton Res., 15: 1035-1051.

Robinson, C. and Williams, P. J. le B. 1999. Plankton net community production and dark respiration in the Arabian Sea during September 1994. Deep-Sea Res. II, 46: 745-766.

Robinson, C., Archer, S., and Williams, P. J. le B. 1999 Microbial dynamics in coastal waters of East Antarctica: plankton production and respiration. Mar. Ecol. Prog. Ser., 180: 23-36.

Robinson, C., Serret, P., Tilstone, G., Teira, E., Zubkov, M. V., Rees, A. P., and Woodward, E. M. S. 2002a. Plankton respiration in the Eastern Atlantic Ocean Deep-Sea Res. I, 49: 787-813.

Robinson, C., Widdicombe, C. E., Zubkov, M. V., Tarran G. A., Miller, A. E. J., and Rees, A. P. 2002b. Plankton community respiration during a coccolithophore bloom Deep-Sea Res. II, 49: 2929-2950.

Roy, S. O. and Packard, T. T. 2001. $\mathrm{CO}_{2}$ production rate predicted from isocitrate dehydrogenase activity, intracellular substrate concentrations and kinetic constants in the marine bacterium Pseudomonas nautical Mar. Biol. 138: 1251-1258.

Sampou, P. and Kemp, W. M. 1994. Factors regulating plankton community respiration in Chesapeake Bay Mar. Ecol. Prog. Ser., 110: 249-258.

Serret, P., Fernandez, E., Sostes, J. A., and Anadon, R. 1999 Seasonal compensation of microbial production and respiration in a temperate sea. Mar. Ecol. Prog. Ser., 187: 43-57.

Serret, P., Robinson, C., Fernandez, E., Teira, E., and Tilstone, G. 2001. Latitudinal variation of the balance between plankton photosynthesis and respiration in the E. Atlantic Ocean. Limnol. Oceanogr., 46: 1642-1652.

Serret, P., Fernandez, E. and Robinson, C. 2002. Biogeographic differences in the net ecosystem metabolism of the open ocean. Ecology, 83: 3225-3234 
Sheldon, R. W., Prakash, A. and Sutcliffe W. H. 1972. The size distribution of particles in the Ocean. Limnol. Oceanogr., 17: 327-340.

Sherr, E. B., Sherr, B. F. and Sigmon, C. T. 1999. Activity of marine bacteria under incubated and in situ conditions. Aquatic Microbial Ecology, 20: 213-223.

Sherry, N. D., Boyd, P. W., Sugimoto, K., and Harrison, P. J. 1999. Seasonal and spatial patterns of heterotrophic bacterial production, respiration, and biomass in the subarctic NE Pacific. Deep-Sea Res., II, 46: 2557-2578.

Smith S. V. and Mackenzie, F. T. C. 1987. The oceans as a net heterotrophic system: implications from the carbon biogeochemical cycle. Glob. Biogeochem. Cyc., 1: 187-198.

Sondergaard, M., Williams, P. J. le B., Cauwet, G., Rieman, B., Robinson, C., Terzic, S., Woodward, E. M. S., and Worm, J. 2000. Net accumulation and flux of dissolved organic carbon and dissolved organic nitrogen in marine plankton communities. Limnol. Oceanogr., 45: 1097-1111.

Straile, D. 1997. Gross growth efficiencies of protozoan and metazoan zooplankton and their dependence on food concentration, predator prey weight ratio and taxonomic group. Limnol. Oceanogr., 42: 1375-1385.

Sullivan, C. W., Arrigo, K. R., McClain, C. A., Comiso, J. C., and Firestone, J. 1993. Distribution of phytoplankton blooms in the Southern Ocean. Science, 262: 1832-1837.

Upstill-Goddard, R. C., Watson, A. J., Wood, J., and Liddicoat, M. I. 1991. Sulfur hexafluoride and ${ }^{3} \mathrm{He}$ as seawater tracers-deployment techniques and continuous underway analysis for sulfur-hexafluoride. Anal. Chim. Acta, 249: 555-562.

Vezina, A. F. and Platt, T. 1988. Food web dynamics in the ocean. I. Best-estimates of flow networks using inverse methods. Mar. Ecol. Prog. Ser., 42: 269-287.

Williams, P. J. le B. 1981. Microbial contribution to overall marine plankton metabolism: direct measurements of respiration. Oceanol. Acta, 4: 359-364.

Williams, P. J. le B. 1982. Microbial contribution to overall plankton community respiration studies in enclosures, In G. D. Grice and M. R. Reeve (eds) Marine Microcosms. Springer-Verlag, Berlin, pp. 305-321.
Williams, P. J. le B. 1995. Evidence for the seasonal accumulation of carbon-rich dissolved organic material, its scale in comparison with changes in particulate material and the consequential effect on net $\mathrm{C} / \mathrm{N}$ assimilation ratios. Mar. Chem., 51: 17-29.

Williams, P. J. le B. 1998. The balance of plankton respiration and photosynthesis in the open oceans. Nature, 394: 55-57.

Williams, P. J. le B. 2000. Net production, gross production and respiration: what are the interconnections and what controls what? In R. B. Hanson, H. W. Ducklow, and J. G. Field (eds) The Changing Ocean Carbon Cycle: A Midterm Synthesis of the Joint Global Ocean Flux Study. Cambridge University Press, Oxford, UK, p. 514.

Williams, P. J. le B. and Bowers, D. G. 1999. Regional carbon imbalances in the oceans. Science, 284: 1735b.

Williams, P. J. le B. and Gray, R. W. 1970. Heterotrophic utilization of dissolved organic compounds in the sea. II: observations on the responses of heterotrophic marine populations to abrupt increase in amino acid concentration J. Mar. Biol. Assoc. UK, 50: 871-881.

Williams, P. J. le B. and Purdie, D. A. 1991. In vitro and in situ derived rates of gross production, net community production and respiration of oxygen in the oligotrophic subtropical gyre of the North Pacific Ocean. Deep-Sea Res. I, 38: 891-910.

Williams, P. J. le B., Morris, P. J., and Karl, D. M. 2004. Net community production and metabolic balance at the oligotrophic ocean site: Station ALOHA. Deep-Sea Res..

Yocis, B. H., Kieber, D. J., and Mopper, K. 2000. Photochemical production of hydrogen peroxide in Antarctic waters Deep-Sea Res. I, 47: 1077-1099.

Yuan, J. C. and Shiller, A. M. 2001. The distribution of hydrogen peroxide in the southern and central Atlantic Ocean Deep-Sea Res. II, 48: 2947-2976.

Zubkov, M. V., Sleigh, M. A., and Burkill, P. H. 2000. Assaying picoplankton distribution by flow cytometry of underway samples collected along a meridional transect across the Atlantic Ocean. Aquat. Microb. Ecol., 21: 13-20. 